\title{
Quantitative Trait Loci (QTL) Underlying Biomass Yield and Plant Height in Switchgrass
}

\author{
Desalegn D. Serba • Guillaume Daverdin • \\ Joseph H. Bouton • Katrien M. Devos • \\ E. Charles Brummer • Malay C. Saha
}

Published online: 30 August 2014

(C) The Author(s) 2014. This article is published with open access at Springerlink.com

\begin{abstract}
Switchgrass (Panicum virgatum L.) biomass yield and feedstock quality improvement are priority research areas for bioenergy feedstock development. Identification of quantitative trait loci (QTL) underlying these traits and of traitlinked markers for application in marker-assisted selection (MAS) is of paramount importance in facilitating switchgrass breeding. Detection of QTL for biomass yield and plant height was conducted on parental linkage maps constructed using a heterozygous pseudo- $\mathrm{F}_{1}$ population derived from a cross between lowland Alamo genotype AP13 and upland Summer genotype VS16. QTL analysis was performed with composite
\end{abstract}

Electronic supplementary material The online version of this article (doi:10.1007/s12155-014-9523-8) contains supplementary material, which is available to authorized users.

D. D. Serba · J. H. Bouton • E. C. Brummer • M. C. Saha Forage Improvement Division, The Samuel Roberts Noble Foundation, 2510 Sam Noble Pkwy, Ardmore, OK 73401, USA

G. Daverdin · J. H. Bouton $\cdot$ K. M. Devos

Institute of Plant Breeding, Genetics and Genomics, Athens, GA, USA

G. Daverdin · J. H. Bouton • K. M. Devos • E. C. Brummer Department of Crop and Soil Sciences, University of Georgia, Athens, GA, USA

G. Daverdin $\cdot$ K. M. Devos

Department of Plant Biology, University of Georgia, Athens, GA 30602, USA

D. D. Serba • G. Daverdin • K. M. Devos • E. C. Brummer •

M. C. Saha $(\square)$

BioEnergy Science Center (BESC), Oak Ridge National Laboratory, Oak Ridge, TN, USA

e-mail: mcsaha@noble.org

Present Address:

E. C. Brummer

Plant Breeding Center, Department of Plant Sciences, University of

California, Davis, One Shields Ave., Davis, CA 95616, USA interval mapping. Four QTL for biomass yield and five QTL for plant height were identified using best linear unbiased predictors across ten and eight environments, respectively. The phenotypic variability explained (PVE) by QTL detected in the across environments analysis ranged from 4.9 to $12.4 \%$ for biomass yield and 5.1 to $12.0 \%$ for plant height. A total of 34 and 38 main effect QTL were detected for biomass yield and plant height, respectively, when data from each environment were analyzed separately. The PVE by individual environment QTL ranged from 3.3 to $15.3 \%$ for biomass yield and from 4.3 to $17.4 \%$ for plant height. In addition, 60 and 51 epistatic QTL were detected for biomass yield and plant height, respectively. Significant QTL by environment interactions were detected for QTL mapped in eight genomic regions for each of the two traits. Seven QTL affected both traits and may represent pleiotropic loci. Overall, 11 genomic regions were identified that were important in controlling biomass yield and/or plant height in switchgrass. The markers linked to the main effect and epistatic QTL may be used in MAS to maximize selection gain in switchgrass breeding, leading to a faster development of better biofuel cultivars.

Keywords Switchgrass - QTL · Biomass yield · Plant height . Epistasis

\section{Introduction}

A renewable, low-carbon transportation fuel could mitigate global climate change that is exacerbated by the burning of fossil fuels [1] by supplementing oil supplies [2] and meeting increased energy demand resulting from global population growth and economic development [3]. Sustainable nextgeneration (lignocellulose-based) feedstocks could supplement or replace current grain-based ethanol production [4] or could be directly burned to produce electricity. 
Switchgrass (Panicum virgatum L.) is a warm season C4 perennial grass native to the North American tall grass prairie [5] that has been identified as a promising feedstock for bioenergy production. Increased energy yield per unit area of switchgrass will improve its utility as a dedicated bioenergy crop [6]; therefore, biomass yield is an important trait in switchgrass breeding. Yield is a complex trait, the result of numerous mostly quantitatively inherited traits, and is greatly affected by the environment [7].

Biomass yield improvements through breeding have been made in switchgrass [8-11]. The primary limitation of conventional plant breeding methods is the length of a selection cycle, which typically requires several years for perennials such as switchgrass in order to assess persistence in the field. Genetic markers offer an appealing alternative selection method. If markers linked to quantitative trait loci (QTL) for key traits were identified, selection for these loci could be done on seedlings and hence at a much earlier stage than selection based on phenotypic evaluations in the field. The use of markers could potentially accelerate genetic gains and lead to the faster development of better biofuel cultivars.

Switchgrass germplasm can be divided into upland and lowland ecotypes, although several subpopulations are present within each of these groups [12]. When the two ecotypes have the same ploidy level, they are interfertile and produce viable progeny. We have previously constructed a genetic map using a biparental population developed by crossing tetraploid genotypes derived from the two ecotypes [13]. Because switchgrass is an allogamous species, individual plants are heterozygous at many loci, and consequently, a pseudo- $F_{1}$ population derived from a biparental cross is segregating for the traits of our interest and can be mapped directly; a limitation of this method is that recombination within each ecotype is mapped, rather than recombination events between the ecotypes. In this experiment, we used the pseudo- $\mathrm{F}_{1}$ mapping population to identify markers linked to QTL associated with biomass yield and plant height that could be used in marker-assisted selection (MAS) and to estimate QTL effects and interactions.

\section{Materials and Methods}

\section{Parental Genotypes and the Mapping Population}

A pseudo- $\mathrm{F}_{1}$ mapping population was developed by crossing two heterozygous parents, 'AP13' and 'VS16', as described by Missaoui et al. [11] and Serba et al. [13]. AP13, the female parent, was a selection from the lowland cultivar 'Alamo'. VS16, the male parent, was a selection from the upland cultivar 'Summer'. AP13 is taller and higher yielding than VS16. A total of 188 full-sib progeny was used for mapping. Each genotype was clonally propagated for multilocationreplicated field evaluations.

\section{Field Experiment and Phenotypic Evaluation}

The population was evaluated at three locations: the Noble Foundation's Research Park at Ardmore, OK (latitude $34.1120^{\circ} \mathrm{N}$, longitude $97.5376^{\circ} \mathrm{W}$ on a Wilson silt loam soil); the Noble Foundation's Red River Farm near Burneyville, OK (latitude $33.9079^{\circ} \mathrm{N}$, longitude $97.2889^{\circ} \mathrm{W}$ on a Minc fine sandy loam); and the University of Georgia's Plant Sciences Farm, Watkinsville, GA (latitude $33.8628^{\circ} \mathrm{N}$, longitude $83.4080^{\circ} \mathrm{W}$ on an Appling coarse sandy loam). The field experiments comprised clones of 251 full-sib progeny, duplicates of the parental genotypes, and an Alamo genotype as a check. The experimental unit in each replication was a single ramet. The experiments in Ardmore and Burneyville were planted in a R-256 honeycomb design [14] with four replications. A randomized complete block design (RCBD) was used at Watkinsville. The field experiments in Ardmore and Burneyville were transplanted on July 19, 2007 and May 08, 2008, respectively. The spacing at Ardmore and Burneyville was $1.5 \mathrm{~m}$ between plants with a row spacing of $1.3 \mathrm{~m}$ and even rows staggered at $0.75 \mathrm{~m}$. At Watkinsville, replicates 1 and 2 were transplanted to the field on September 25, 2007, and replicates 3 and 4 were transplanted immediately adjacent to the first two replications on April 30, 2008, at a spacing of $96.5 \mathrm{~cm}$ centers.

The experiments were planted on finely prepared seedbeds. Prior to establishment, a soil test was conducted and NPK fertilizer was incorporated based on the soil test index recommendations for Oklahoma (www.osufacts.okstate.edu) and for Georgia (http://aesl.ces.uga.edu). Nitrogen was applied in early spring each year at the rate of $112 \mathrm{~kg} \mathrm{~N} \mathrm{ha}^{-1}$. Supplemental irrigation was only provided to the plants during establishment. Weed control was conducted using two pre-emergent herbicides: Prowl $\mathrm{H}_{2} \mathrm{O}$ [a.i. pendimethalin: $N$-(1-ethylpropyl)-3-4-dimehyl-2, 6-dinitrobenzenamine (38. $7 \%$ )] (BASF Corporation, Research Triangle Park, NC) at the rate of $2.34 \mathrm{~L} \mathrm{ha}^{-1}$ and DualMagnam [a.i. S-metolachlor, 83. $7 \%$ ] (Syngenta Crop Protection, LLC, Greensboro, NC) at the rate of $1.5 \mathrm{~L} \mathrm{ha}^{-1}$. Broadleaf herbicide (2,4-D) was applied as needed. Interplant cultivation in Oklahoma was practiced during the first 2 years after establishment using a Multivator (Model FPSREs .50) (www.rmwade.com). After 2 years, the plants expanded and interplant space became too narrow for cultivation.

Phenotypic data were collected from 2008 to 2011 at Ardmore and from 2009 to 2011 at Burneyville. At Watkinsville, biomass yield data were collected from 2009 to 2011, while plant height was measured only in 2009. Plant height was measured before harvest from the base of the plant to the top of the panicle and recorded in centimeters $(\mathrm{cm})$. Biomass was harvested after senescence either by hand or using a customized silage chopper (John Deere Forage Harvester C1200). The harvested biomass of each plant was collected in a bucket 
and weighed in kilograms. At Ardmore and Burneyville, fresh biomass yield data were used for QTL analysis. The QTL analysis for biomass from Watkinsville was based on dry biomass yield obtained after oven-drying of the samples for $72 \mathrm{~h}$ at $45^{\circ} \mathrm{C}$.

\section{Phenotypic Data Analysis}

Phenotypic data were analyzed using the SAS $9.3{ }^{\circledR}$ statistical program (SAS Institute, Cary, NC). Normality for each of the traits was determined using the univariate procedure. An overall mixed model analysis of variance was conducted considering replication within location, year, year $\times$ location, genotype, year $\times$ genotype, location $\times$ genotype, and year $\times$ location $\times$ genotype as random effects and location as a fixed effect. Because of a significant genotype $\times$ environment interaction $(\mathrm{G} \times \mathrm{E})$, we generated best linear unbiased predictors (BLUP) [15] for across environments data. To generate the BLUP, years, locations, replications, and their interactions were considered fixed effects [16]. An analysis of variance for each individual environment (a location-year combination) was also conducted to generate least square means for genotypes in each environment. Correlation of plant height and biomass yield was assessed using the BLUP for the traits. Statistical significance was assessed at the $5 \%$ probability level unless indicated otherwise.

\section{Linkage Map and QTL Analysis}

The previously constructed linkage maps in this population using simple sequence repeat (SSR), sequence-tagged site (STS), and Diversity Array Technology (DarT) markers [13] were used for the QTL analysis. Before QTL analysis, markers that cosegregated were reduced to a single marker by retaining the marker with the least missing data or, if multiple cosegregating markers had the same number of data points, by randomly selecting one of the cosegregating markers. The linkage groups (LGs) were designated I to IX followed by "a" or "b" to arbitrarily represent the two subgenomes of switchgrass and " $\mathrm{f}$ " or " $\mathrm{m}$ " referring to the female and male map, respectively. The female map represents recombination events that took place within the heterozygous lowland AP13 parent, and the male map represents recombination events that took place within the heterozygous upland VS16 parent.

The QTL analysis was conducted using WinQTL Cartographer version 2.5 [17]. Since the $\mathrm{G} \times \mathrm{E}$ interaction was significant, least square means of individual genotypes in each environment and BLUP generated across all environments were used as phenotypic data. Initially, marker-trait associations were tested using a single marker analysis [18]. Simple interval mapping [19] was performed using the single QTL model and the expectation maximization (EM) algorithm.
QTL were then confirmed by composite interval mapping (CIM) using the following model [20]:

$y_{i}=\mu+Z_{i} B+\sum_{r=1}^{m} X_{i r} \beta_{r}+\varepsilon_{i}$

where $y_{i}$ is the trait phenotypic value of genotype $i ; \mu$ is the across environments mean; $B$ is a column vector for the effects of a putative QTL where only the additive effect is estimated in a backcross (when the marker is present it shows a positive sign, when absent a negative sign); $Z_{i}$ is a row vector of predictor variables corresponding to the effects of the putative QTL; $X_{i r}$ is a row vector of predictor variables corresponding to the $r$ th cofactor marker; $\beta_{r}$ is a column vector with the coefficient of the $r$ th cofactor marker; and $\varepsilon$ is the random error that is assumed to follow a normal distribution with mean zero and variance $\sigma^{2}$.

The CIM was performed with a forward and backward stepwise regression at a threshold of $p<0.05$ for cofactor selection, a window size of 10 , and a $1.0 \mathrm{cM}$ walking speed along the LG. QTL with a logarithm of odds (LOD) score of 2.5 and above were reported as QTL, while the genome-wide threshold of significance $(p<0.05)$ determined with 1,000 times permutation analysis ranged from LOD score 3.1 to 3.9.

Inclusive composite interval mapping (ICIM) of digenic epistasis [21] was conducted to estimate the effect of a putative QTL using estimated positions of other QTL as a covariate and to model interaction (epistasis) effects. QTL $\times$ environment interaction $(\mathrm{Q} \times \mathrm{E})$ and epistatic $\mathrm{QTL}$ analyses were performed using the ICIM software [21, 22]. The $\mathrm{Q} \times \mathrm{E}$ analysis was conducted using the QTL IciMapping algorithm for multi-environment trials (MET) [17]. The following model was implemented to illustrate the theoretical basis for mapping epistasis in ICIM:

$y_{i}=\mu+\sum_{r=1}^{m} b_{j} x_{i j}+\sum_{r<k}^{p} b_{j k} x_{i j} x_{i k}+\varepsilon_{i}$

where all variables are as above except the following: $b_{j}$ is the partial regression coefficient of the phenotype on the $j$ th marker variable; $x_{i j}$ is a dummy variable for the genotype of the $i$ th individual at the $j$ th marker; $b_{j k}$ is the partial regression coefficient of the phenotype on the multiplication variable of the $j$ th and $k$ th markers; and $x_{i j}$ and $x_{i k}$ are the epistatic effect between QTL pair $j$ and $k$, taking value 1 for homozygote marker types, and -1 for heterozygotes.

QTL designations were made using abbreviations for the trait $($ by $=$ biomass yield and, $\mathrm{ph}=$ plant height), the linkage group name (in Arabic numerals), followed by year and location $(\mathrm{A}=$ Ardmore, $\mathrm{B}=$ Burneyville, $\mathrm{W}=$ Watkinsville $)$ at which the QTL was mapped; when more than one QTL was detected on a LG, a serial number suffix was added. QTL 
Table 1 Combined analysis of variance for biomass yield and plant height data for the AP13 $\times$ VS16 mapping population evaluated at Ardmore (2008 to 2011) and Burneyville (2009 to 2011) in Oklahoma and Watkinsville (2009 to 2011) in Georgia

\begin{tabular}{|c|c|c|c|}
\hline Sources & $d f$ & Biomass yield & Plant height \\
\hline & & \multicolumn{2}{|c|}{ Expected mean squares ${ }^{a}$} \\
\hline Replication (location) & 9 & $2.56^{* *}(1.5)$ & $4,304.68 * *(1.6)$ \\
\hline Year & 3 & $127.82 * *(11.7)$ & $76,379.00 * *(39.3)$ \\
\hline Year $\times$ location & 6 & $22.85 * *(10.0)$ & $48,047.00 * *(7.8)$ \\
\hline Genotype & 187 & $0.85^{* *}(21.1)$ & $1,406.50 * *(9.6)$ \\
\hline Year $\times$ genotype & 561 & $0.09(2.3)$ & $262.18 * *(1.4)$ \\
\hline Location $\times$ genotype & 374 & $0.43^{* *}(9.0)$ & $478.24 * *(1.4)$ \\
\hline $\begin{array}{l}\text { Year } \times \text { location } \times \\
\text { genotype }\end{array}$ & 562 & $0.07(0.1)$ & $266.88 * *(0.3)$ \\
\hline \multirow[t]{2}{*}{ Residual } & 4,940 & $0.08(23.7)$ & $193.63(18.4)$ \\
\hline & & \multicolumn{2}{|c|}{ Fixed effect ( $F$ value) } \\
\hline Location & 2 & $3,612.00 * *(20.6)$ & $10.32 * *(20.3)$ \\
\hline
\end{tabular}

$d f$ degrees of freedom

$* * p=0.01$

${ }^{\mathrm{a}}$ The values in the bracket indicate variance component in percent detected with the across environments BLUP were denoted with a "BLUP" suffix instead of year and location.

\section{Results and Discussion}

Phenotypic Performance and Variations

The across environments analysis of variance indicated significant differences among years $(\mathrm{Y})$, locations $(\mathrm{L})$, and genotypes $(\mathrm{G})$ (Table 1). In addition, $\mathrm{Y} \times \mathrm{L}$ and $\mathrm{L} \times \mathrm{G}$ interactions were significant for biomass yield, while $Y \times L, Y \times G, L \times G$, and $\mathrm{Y} \times \mathrm{L} \times \mathrm{G}$ interactions were significant for plant height. The two parents differed considerably for biomass yield and plant height (Table 2), with AP13, a lowland genotype, being taller and higher yielding than VS16 which was selected from an upland ecotype.

Biomass yield of the population was normally distributed in most of the environments (Fig. 1) and varied from 0.01 to $6.79 \mathrm{~kg}$ plant $^{-1}$ with a mean of $0.89 \mathrm{~kg}$ plant $^{-1}$ across environments (Table 2). Significant biomass yield differences by location (L), cultivar $(\mathrm{C})$, year $(\mathrm{Y}), \mathrm{Y} \times \mathrm{L}$, and $\mathrm{C} \times \mathrm{Y} \times \mathrm{L}$ were

Table 2 Summary of biomass yield and plant height data for the AP13 $\times$ VS16 mapping population compared to parental performance as evaluated at Ardmore (2008 to 2011) and Burneyville (2009 to 2011) in Oklahoma and Watkinsville (2009 to 2011) in Georgia

\begin{tabular}{|c|c|c|c|c|c|c|c|c|}
\hline \multirow[t]{2}{*}{ Parameter } & \multicolumn{4}{|c|}{ Biomass yield (kg plant $\left.{ }^{-1}\right)$} & \multicolumn{4}{|c|}{ Plant height (cm) } \\
\hline & 2008 & 2009 & 2010 & 2011 & 2008 & 2009 & 2010 & 2011 \\
\hline \multicolumn{9}{|l|}{ Ardmore } \\
\hline AP13 & 1.10 & 1.59 & 3.39 & 2.24 & 191 & 188 & 210 & 144 \\
\hline VS16 & 0.08 & 0.02 & 0.20 & 0.21 & 101 & 106 & 123 & 86 \\
\hline Population mean & 0.53 & 0.69 & 1.21 & 0.75 & 165 & 154 & 174 & 140 \\
\hline Population range & $0.01-1.50$ & $0.40-1.03$ & $0.04-3.16$ & $0.02-2.26$ & $34-212$ & $138-159$ & $58-236$ & $15-178$ \\
\hline SE & 0.09 & 0.11 & 0.13 & 0.11 & 8.9 & 5.6 & 5.4 & 5.6 \\
\hline LSD (0.05) & 0.25 & 0.31 & 0.38 & 0.30 & 21.2 & 15.8 & 16.0 & 16.4 \\
\hline \multicolumn{9}{|l|}{ Burneyville } \\
\hline AP13 & - & 3.27 & 4.49 & 4.36 & - & 215 & 244 & 174 \\
\hline VS16 & - & 0.09 & 0.21 & 0.42 & - & 126 & 153 & 75 \\
\hline Population mean & - & 0.89 & 1.52 & 1.60 & - & 177 & 204 & 148 \\
\hline Population range & - & $0.03-4.23$ & $0.04-6.79$ & $0.04-4.86$ & - & $96-230$ & $124-285$ & $37-217$ \\
\hline $\mathrm{SE}$ & - & 0.17 & 0.23 & 0.290 & - & 6.1 & 6.6 & 5.9 \\
\hline $\operatorname{LSD}(0.05)$ & & 0.52 & 0.66 & 0.85 & & 16.6 & 19.3 & 17.7 \\
\hline \multicolumn{9}{|l|}{ Watkinsville } \\
\hline AP13 & - & 0.37 & 1.27 & 0.99 & - & 133 & - & - \\
\hline VS16 & - & 0.03 & 0.11 & - & - & 81 & - & - \\
\hline Population mean & - & 0.28 & 0.74 & 0.67 & - & 126 & - & - \\
\hline Population range & - & $0.01-0.93$ & $0.02-2.46$ & $0.05-1.97$ & - & $64-168$ & - & - \\
\hline $\mathrm{SE}$ & - & 0.06 & 0.12 & 0.10 & - & 5.9 & - & - \\
\hline $\operatorname{LSD}(0.05)$ & & 0.17 & 0.35 & 0.30 & & 16.9 & & \\
\hline
\end{tabular}

$S E$ standard error of population mean 
Fig. 1 Frequency distribution of biomass yield data from 2008 to 2011 at Ardmore, OK and from 2009 to 2011 at Burneyville, OK and Watkinsville, GA
Ardmore 2008
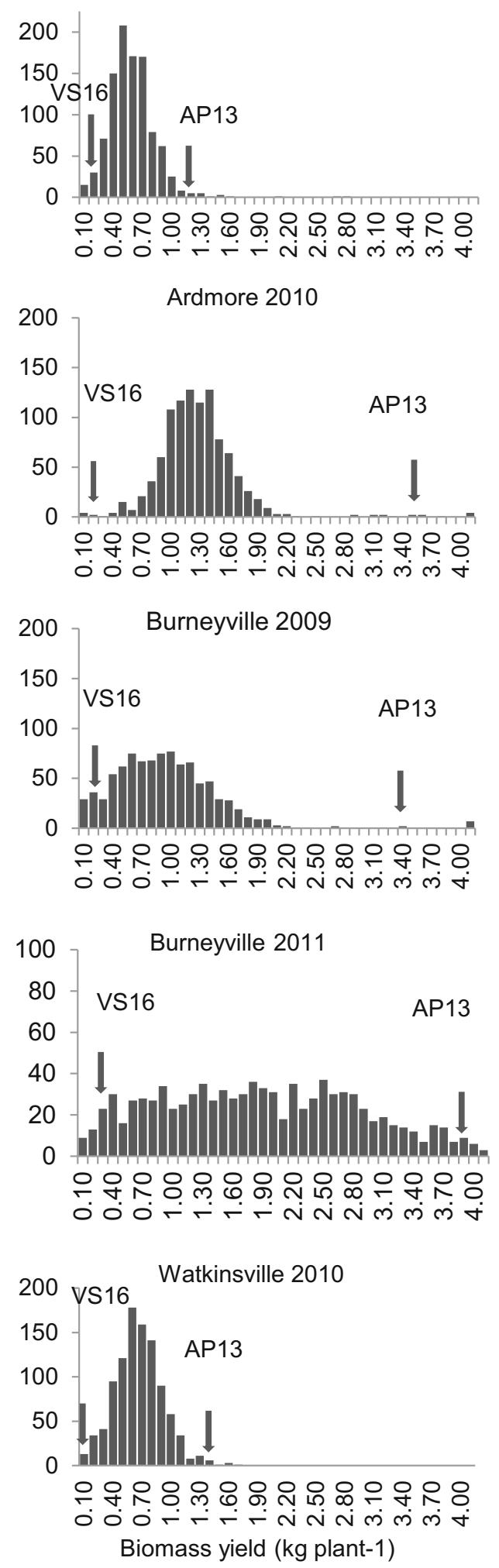
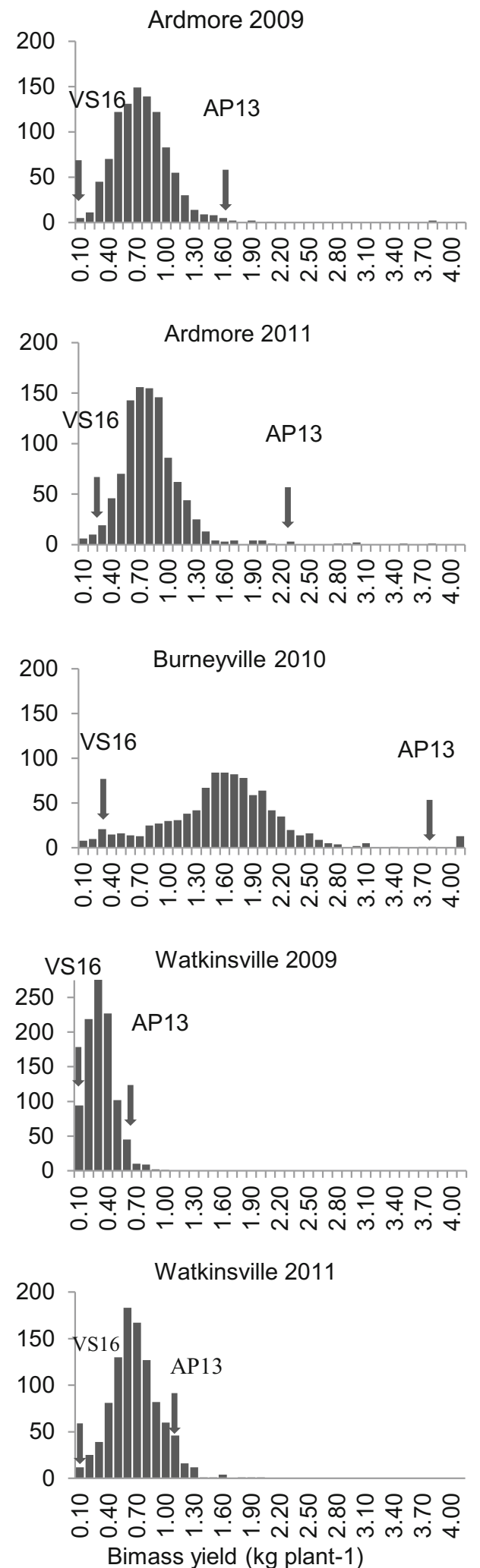

reported for switchgrass cultivars and cultivar blends evaluated at two Oklahoma locations over 7 years (1994-2000) [23]. Biomass yield differences with high $\mathrm{G} \times \mathrm{E}$, largely caused by location differences rather than by variation across years or harvest dates, were reported for switchgrass cultivars grown in southern Wisconsin and eastern South Dakota [24]. Biomass 
Fig. 2 Frequency distribution graph of plant height data from 2008 to 2011 at Ardmore, OK and from 2009 to 2011 at Burneyville, OK and for 2009 at Watkinsville, GA
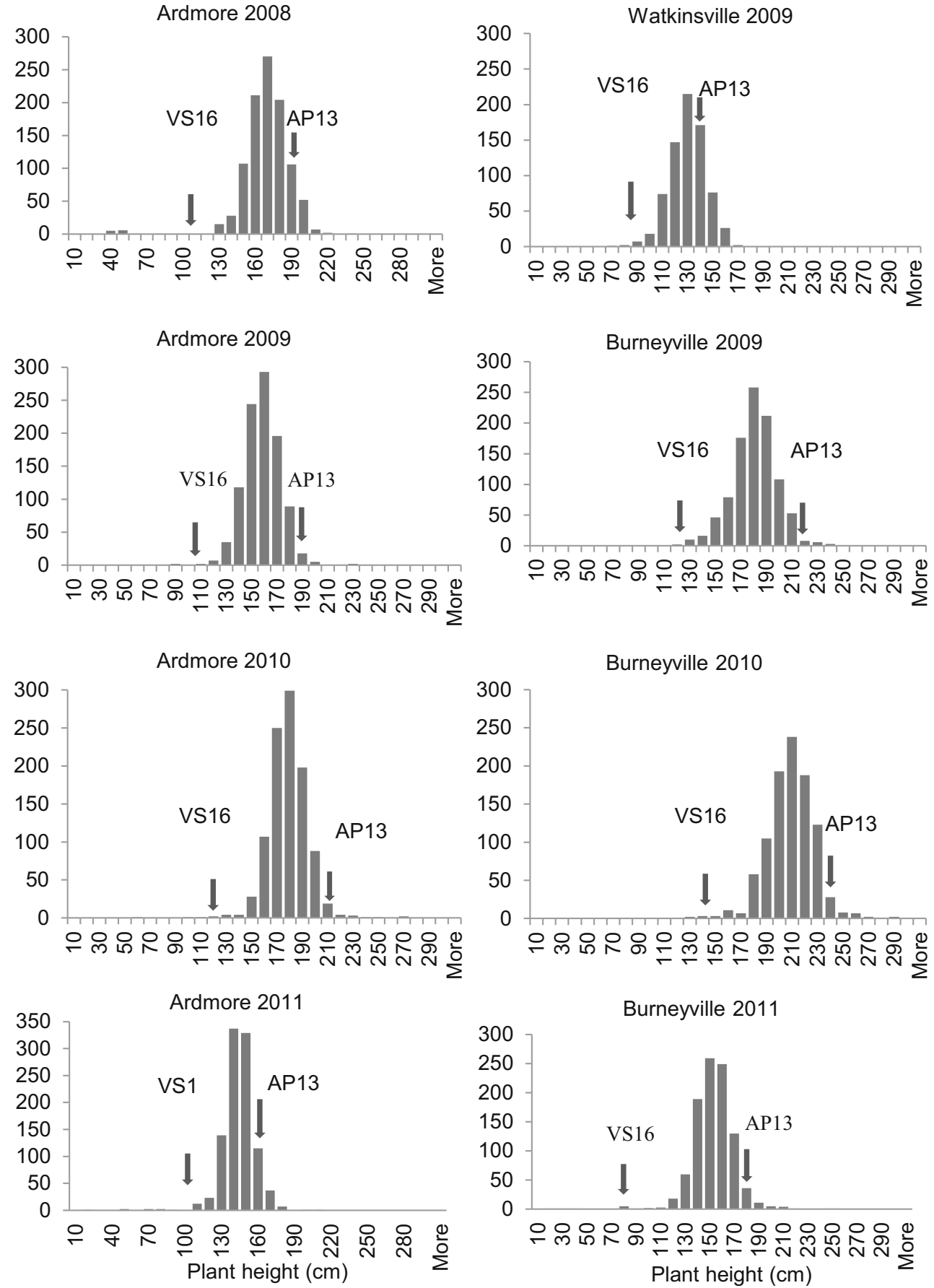

yield variations among half-sib families of different background with significant family-by-year and family-by-block interactions were also reported in switchgrass [25]. The significant genotype, location, year, $\mathrm{Y} \times \mathrm{L}$, and $\mathrm{L} \times \mathrm{G}$ effects that we observed in the AP13 $\times$ VS16 full-sib pseudo- $\mathrm{F}_{1}$ population for biomass yield are in agreement with the previous reports. Our data also demonstrate the considerable influence of the environment on biomass production in switchgrass.

Differences among years and among locations for plant height were observed. In general, plants were shorter in
2011 due to drought conditions in Oklahoma. However, the reduction in plant height did not lead to a yield reduction in Burneyville probably because late rainfall enabled the plants to produce more tillers. Plant height was distributed normally in the population in all the test environments (Fig. 2). Genotypic variation for plant height was present in the population, with the height of the AP13 $\times$ VS16 progeny ranging from 34 to $285 \mathrm{~cm}$ with a mean of $161 \mathrm{~cm}$. Most of the progeny had phenotypic values between the two parents although some transgressive segregation was observed in the population. 


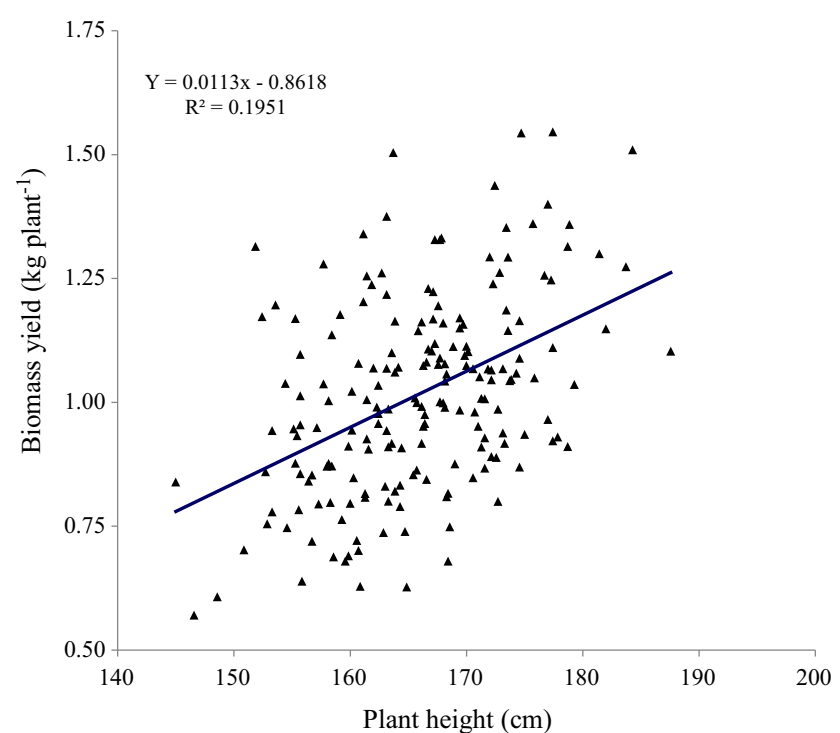

Fig. 3 Correlation between plant height and biomass yield as revealed by simple linear regression using across environment mean values

Plant height exhibits wide variability in switchgrass populations and is considered a main contributing trait for biomass yield improvement [8]. Contrasting variation in plant height was reported for upland and lowland switchgrass varieties grown in different locations in the Mediterranean region [26] implying the influence of environment on the trait.

Biomass yield and plant height were positively correlated $(r=0.45, p<0.01)$ across all environments. A simple linear regression of the mean biomass yield on plant height showed that a unit $(1 \mathrm{~cm})$ increase in plant height increased biomass yield by $0.01 \mathrm{~kg}$ plant $^{-1}$ (Fig. 3). The coefficient of determination $\left(r^{2}=0.195\right)$ indicated that about $20 \%$ of biomass variation is accounted for by plant height alone. Plant height is among the most important biomass yield components in energy grasses [27] and was found to be a good predictor of maize (Zea mays L.) biomass yield in different environments [28]. As compared to switchgrass height which was measured per plant, maize height in the above case was averaged per plot at commercial planting density. Consequently, the correlation of plant height with biomass yield may be lower in space-planted switchgrass than might be expected under commercial density in maize.

\section{QTL for Biomass Yield}

The female (lowland) and male (upland) maps used for the QTL analysis had 18 and 17 LGs, respectively [13]. After removal of cosegregating loci, the female map contained 393 loci and the male map contained 288 loci. QTL for biomass yield were detected on LGs VIa-f, IXb-f, IIIa-m, and IXb-m across all environments analysis using BLUP (Table 3; Fig. 4). Corresponding QTL were also detected in multiple individual environments using a least square means analysis (Table 3;
Fig. 4). The phenotypic variation explained (PVE) by individual QTL detected in the across environments analysis ranged from 4.9 to $12.4 \%$ with additive effects of -0.28 to $0.18 \mathrm{~kg}$ plant $^{-1}$. The two largest QTL, by9b-f.BLUP and by4bm.BLUP, had PVE of 12.4 and 8.1 and additive effects of -0.28 and $-0.23 \mathrm{~kg}$ plant $^{-1}$, respectively. Across single environments, QTL for biomass yield were mapped on 11 of the 18 female LGs and 10 of the 17 male LGs and were found in all nine homoeology groups (HGs). Using the least square means of individual environments, 34 main effect QTL were mapped for biomass yield over ten environments (Table 3). Twenty-one of the individual environment QTL for biomass yield were detected in the female map and 13 were detected in the male map. In addition, 9 and 13 QTL with LOD threshold between 1.4 and 2.4 were detected, respectively, in the female and male maps, mostly in genomic regions that carried QTL in other environments (Table 3). These QTL with lower LOD score indicate genomic regions associated with biomass yield.

The additive effects of the biomass yield QTL mapped in individual environments ranged from -0.29 to $0.21 \mathrm{~kg}$ plant $^{-1}$. The PVE of individual QTL for biomass yield ranged from 3.3 to $15.3 \%$ with four QTL explaining more than $10 \%$ of the phenotypic variations each. The QTL, by9b-f.11B, had the largest PVE (15.3\%) followed by by3a-m.09B1 (14.7\%), by3a-m.09B2 (11.5\%), and by9b-m.11B (10.7\%). These four QTL had negative additive effects of $-0.29,-0.29,-0.26$, and $-0.25 \mathrm{~kg}$ plant $^{-1}$, respectively. The biomass QTL detected on LGs IIb-f, VIa-f, IXa-f, IXb-f, IIIa-m, and IXb-m were consistent across two or more environments with slight shifts in position mainly due to significant $\mathrm{Q} \times \mathrm{E}$ interactions (Table 3; Fig. 4). QTL on IVb-m and VIa-f had less interaction with the environments. In addition to the main effect QTL, 60 additive $\times$ additive epistatic QTL (excluding the main effect) were also detected for biomass yield (LOD score $\geq 5.0$ ) (Supplementary Table 1). The additive $\times$ additive epistatic QTL effects were ranging from -0.17 to $0.18 \mathrm{~kg} \mathrm{plant}^{-1}$.

Biomass QTL mapping has been conducted in several crops with the purpose of identifying genomic regions and genetic loci underlying bioenergy feedstock yield in populus (Populus tremula L.) [29, 30], poplar (Liriodendron tulipifera L.) [31], and maize [32]; forage yield in inter-subspecific hybrid populations of tetraploid alfalfa (Medicago sativa L.) $[33,34]$, doubled haploid population of rice (Oryza sativa L.) derived from an inter-subspecific cross [35], and in perennial ryegrass (Lolium perenne L.) inbred derived $\mathrm{F}_{2}$ population [36]; or sugar yield in sugarcane (Saccharum officinarum L.) [37-39]. These previous studies in different species and population types reported the prevalence of additive main effects, digenic epistasis, QTL by environment interactions, multiple minor effects, QTL distributed over several genomic regions, and both parents contributing favorable and unfavorable alleles irrespective of their biomass yield potential. 
Table 3 Biomass yield QTL identified in the AP13 $\times$ VS16 switchgrass mapping population using least square means at each environment and across all environments based on best linear unbiased predictions (BLUP) estimates

\begin{tabular}{|c|c|c|c|c|c|c|c|}
\hline Map & QTL name & LG & Position & $\mathrm{LOD}^{\mathrm{a}}$ & $\mathrm{LOD}(\mathrm{Q} \times \mathrm{E})$ & PVE & Additive effect $\left(\mathrm{kg} \mathrm{plant}^{-1}\right)$ \\
\hline \multirow[t]{33}{*}{ Female } & by6a-f.blup & VIa-f & 18.2 & 2.2 & - & 4.9 & 0.18 \\
\hline & by9b-f.blup & IXb-f & 31.6 & 6.1 & - & 12.4 & -0.28 \\
\hline & by $7 b-f .11 B$ & VIIb-f & 0 & 3.0 & - & 5.9 & 0.21 \\
\hline & by6a-f.10B & VIa-f & 20.2 & 2.6 & - & 5.6 & 0.20 \\
\hline & by6a-f.11B & VIa-f & 25.2 & 3.0 & - & 6.0 & 0.18 \\
\hline & by5a-f.11W & Va-f & 121.1 & 2.6 & 7.2 & 6.0 & 0.07 \\
\hline & by $2 b-f .08 A$ & IIb-f & 56.9 & 2.7 & 5.4 & 4.9 & -0.05 \\
\hline & by7b-f.08A & VIIb-f & 29.1 & 3.8 & 3.0 & 7.4 & -0.06 \\
\hline & by9b-f.08A & IXb-f & 36.7 & 4.5 & 5.5 & 8.4 & -0.07 \\
\hline & by9b-f.11W & IXb-f & 24.6 & 2.5 & - & 6.2 & -0.07 \\
\hline & by $2 b-f .09 A$ & IIb-f & 52.6 & 3.0 & 5.4 & 5.6 & -0.08 \\
\hline & by $2 b-f .11 A$ & IIb-f & 54 & 3.0 & 5.4 & 5.8 & -0.09 \\
\hline & by9b-f.10W & $\mathrm{IXb}-\mathrm{f}$ & 119 & 2.7 & 4.3 & 5.5 & -0.10 \\
\hline & by $2 b-f .10 W$ & IIb-f & 47.4 & 4.1 & 5.4 & 8.8 & -0.13 \\
\hline & by9a-f.09A & IXa-f & 25.4 & 4.5 & 4.8 & 9.7 & -0.16 \\
\hline & by3b-f.09B & IIIb-f & 20.5 & 2.9 & - & 5.9 & -0.18 \\
\hline & by2a-f.09B & IIa-f & 34.7 & 3.3 & 2.8 & 6.6 & -0.20 \\
\hline & By9a-f.10B1 & IXa-f & 25.4 & 2.7 & 4.8 & 5.6 & -0.21 \\
\hline & by9a-f.10B2 & IXa-f & 32 & 3.5 & - & 6.6 & -0.22 \\
\hline & by9b-f.09B & IXb-f & 28.7 & 4.5 & - & 9.7 & -0.24 \\
\hline & by $9 b-f .10 B$ & IXb-f & 27.6 & 4.0 & 5.5 & 9.4 & -0.26 \\
\hline & by5a-f.09B & Va-f & 60.4 & 4.4 & 2.7 & 8.1 & -0.27 \\
\hline & by9b-f.11B & IXb-f & 29.6 & 6.8 & 5.5 & 15.3 & -0.29 \\
\hline & \multicolumn{7}{|c|}{ Additional QTL with LOD score 1.9 to 2.4} \\
\hline & by $3 b-f .10 W$ & IIIb-f & 66.9 & 2.4 & - & 5.3 & 0.10 \\
\hline & by4a-f.11W & IVa-f & 21.6 & 2.4 & - & 5.1 & -0.06 \\
\hline & by 5 b-f.08A & Vb-f & 80.9 & 2.3 & 5.0 & 5.0 & 0.05 \\
\hline & by9b-f.09A & $\mathrm{IXb}-\mathrm{f}$ & 37.7 & 2.3 & 5.5 & 4.5 & -0.07 \\
\hline & by3a-f.10A & IIIa-f & 70.9 & 2.3 & 2.7 & 4.5 & -0.09 \\
\hline & by3a-f.10W & IIIa-f & 60.6 & 2.3 & - & 4.5 & 0.09 \\
\hline & by9a-f.10A & IXa-f & 25.4 & 2.2 & 4.8 & 4.6 & -0.09 \\
\hline & by9a-f.11A & IXa-f & 25.4 & 2.2 & 4.8 & 4.4 & -0.07 \\
\hline & by9b-f.10A & IXb-f & 80.2 & 1.9 & 2.9 & 4.8 & -0.09 \\
\hline \multirow[t]{15}{*}{ Male } & by3a-m.blup & IIIa-m & 18.0 & 2.3 & - & 6.1 & -0.20 \\
\hline & by9b-m.blup & IXb-m & 138.8 & 3.3 & - & 8.1 & -0.23 \\
\hline & by $9 b-m .08 A 2$ & $\mathrm{IXb}-\mathrm{m}$ & 35.2 & 4.1 & 4.0 & 9.3 & 0.08 \\
\hline & by $2 b-m .08 A$ & IIb-m & 74.5 & 2.6 & - & 5.4 & 0.05 \\
\hline & by $9 b-m .08 \mathrm{~A} 1$ & $\mathrm{IXb}-\mathrm{m}$ & 2.0 & 2.7 & - & 6.2 & -0.07 \\
\hline & by3a-m.09A1 & IIIa-m & 101.2 & 2.6 & - & 5.7 & -0.08 \\
\hline & by3a-m.11A1 & IIIa-m & 45.4 & 2.7 & - & 5.9 & -0.09 \\
\hline & by5a-m.09B & Va-m & 51.6 & 2.8 & - & 4.9 & -0.17 \\
\hline & by $9 b-m .10 B$ & IXb-m & 140.8 & 2.6 & - & 5.9 & -0.21 \\
\hline & by3a-m.10B3 & IIIa-m & 63.3 & 3.0 & - & 7.0 & -0.23 \\
\hline & by $3 a-m .10 B 2$ & IIIa-m & 53.7 & 3.6 & 2.6 & 7.8 & -0.24 \\
\hline & by9b-m.11B & IXb-m & 139.8 & 4.5 & - & 10.7 & -0.25 \\
\hline & by3a-m.10B1 & IIIa-m & 34.6 & 2.8 & 3.6 & 8.5 & -0.25 \\
\hline & by3a-m.09B2 & IIIa-m & 59.3 & 6.2 & 2.6 & 11.5 & -0.26 \\
\hline & by3a-m.09B1 & IIIa-m & 35.6 & 5.7 & 3.6 & 14.7 & -0.29 \\
\hline
\end{tabular}


Table 3 (continued)

\begin{tabular}{|c|c|c|c|c|c|c|c|}
\hline Map & QTL name & LG & Position & $\mathrm{LOD}^{\mathrm{a}}$ & $\mathrm{LOD}(\mathrm{Q} \times \mathrm{E})$ & PVE & Additive effect $\left(\mathrm{kg} \mathrm{plant}^{-1}\right)$ \\
\hline & \multicolumn{7}{|c|}{ Additional QTL with LOD score 1.4 to 2.4} \\
\hline & by3a-m.09A2 & IIIa-m & 9.0 & 2.4 & - & 8.0 & -0.10 \\
\hline & by $3 a-m .11 A 2$ & IIIa-m & 60.3 & 2.4 & 2.6 & 5.0 & -0.08 \\
\hline & by3a-m.11W & IIIa-m & 53.7 & 2.4 & 2.6 & 5.3 & -0.06 \\
\hline & by8a-m.10A & VIIIa-m & 4.5 & 2.2 & - & 6.1 & -0.10 \\
\hline & by $4 b-m .10 B$ & IVb-m & 65.0 & 2.2 & - & 4.5 & 0.19 \\
\hline & by9a-m.10W & IXa-m & 16.1 & 2.2 & - & 4.7 & 0.09 \\
\hline & by1b-m.09B & $\mathrm{Ib}-\mathrm{m}$ & 82.3 & 2.0 & - & 3.3 & 0.14 \\
\hline & by3a-m.10A & IIIa-m & 59.3 & 2.0 & 2.6 & 3.9 & -0.08 \\
\hline & by3a-m.10W & IIIa-m & 53.7 & 1.8 & 2.6 & 3.9 & -0.08 \\
\hline & by6a-m.11W & VIa-m & 45.8 & 1.8 & - & 4.2 & -0.06 \\
\hline & by $8 b-m .11 W$ & VIIIlb-m & 67.8 & 1.8 & 3.3 & 4.0 & -0.06 \\
\hline & by $5 \mathrm{~b}-\mathrm{m} .10 \mathrm{~W}$ & Vb-m & 2.4 & 1.6 & - & 3.5 & 0.08 \\
\hline & by $8 b-m .09 W$ & VIIIb-m & 9.4 & 1.4 & - & 3.5 & 0.04 \\
\hline
\end{tabular}

The QTL name designation starts with the trait abbreviation (by biomass yield), followed by linkage group number (1 to 9), subgenome designation ("a" or "b"), parental origin of LG ( $f$ female and $m$ male), last two digits of year in which phenotyping was conducted ( 08 to 11$)$ and ends with the location abbreviation ( $A$ Ardmore, OK; $B$ Burneyville, OK; and $W$ Watkinsville, GA). QTL detected with the BLUP data were suffixed with BLUP instead of year and location designation

$L O D(A)$ logarithm of odds for the additive effect, $L O D(Q \times E)$ logarithm of odds for the QTL $\times$ environment effect, "--" data not available. PVE phenotypic variation explained

${ }^{a}$ QTL with LOD score range 1.4 to 2.4 were included

\section{QTL for Plant Height}

A total of five QTL were identified using BLUP data across all environments, two of which were mapped on female LGs and three on male LGs (Table 4; Fig. 4). The PVEs ranged from 5.1 to $12.0 \%$ with additive effects ranging from -8.3 to $6.7 \mathrm{~cm}$ plant $^{-1}$. The QTL ph1b-f.blup and ph9b-m.blup had positive additive effects of 6.7 and $5.4 \mathrm{~cm}$ plant $^{-1}$, respectively. The others had negative effects ranging from -8.3 to $-5.5 \mathrm{~cm} \mathrm{plant}^{-1}$. All five QTL were also detected in one or more individual environments. It is presumed that the QTL detected in both individual environments (least square analysis per environment) and across environments (BLUP analysis across environments) are consistent QTL that may be expressed irrespective of any environmental effect [40, 41].

In the individual environment analysis, a total of 38 main effect QTL were detected for plant height in eight environments at LOD scores 2.5 and above (Table 4). Fifteen of these were detected in the female map and 23 were detected in the male map. An additional seven QTL were detected for plant height at LOD scores between 2.0 and 2.5 in genomic regions of both maps mostly where QTL were detected in other environments (Table 4). These low LOD score QTL indicate genomic regions influencing plant height in switchgrass. The PVE for individual plant height QTL ranged from 4.3 to $17.4 \%$. Most of the height QTL explained less than $10 \%$ of the phenotypic variation, except ph1b-f.09A, ph4a-m.09A, and ph4a-m.11B which explained 17.4, 13.7, and $12.0 \%$, respectively.

Out of the 18 plant height QTL (including QTL with LOD $<2.5)$ that mapped to the female map, 13 had positive additive effects ranging from 4.0 to $8.0 \mathrm{~cm} \mathrm{plant}^{-1}$. Ph1b-f.09A and ph1b-f.09B had the highest positive additive effects of $8.0 \mathrm{~cm}$ plant $^{-1}$ each. The remaining five had negative effects ranging from -4.8 to $-7.1 \mathrm{~cm} \mathrm{plant}^{-1}$ (Table 3).

Eight of the QTL detected on the male map (including QTL with $\mathrm{LOD}<2.5$ ) had positive additive effects ranging from 4.1 to $6.8 \mathrm{~cm}$ plant $^{-1}$. Nineteen QTL had negative effects on plant height ranging from -3.9 to $-8.2 \mathrm{~cm} \mathrm{plant}^{-1}$. The QTL mapped on Ib-f and IVa-m were consistently identified across multiple environments and had positive and negative effects, respectively, on the trait (Fig. 5). It was reported that four out of five QTL detected for plant height in Miscanthus sinensis Andersson had negative effects on the trait [42]. These negative additive effects probably imply the presence of dwarfing genes as reported in sorghum (Sorghum bicolor $\mathrm{L}$.) where four dwarfing genes [43] and an epistatic dwarfing QTL (sbHT9.1) were mapped [44]. In a pseudo- $\mathrm{F}_{1}$ population, height loci that segregate within lowland switchgrass (heterozygous in the AP13 parent) and loci that segregate within upland switchgrass (heterozygous in the VS16 parent) are mapped. However, height loci that vary between lowland (AP13) and upland (VS16) switchgrass are fixed within an ecotype and do not segregate in this type of population. Therefore, QTL with 


$\left.\begin{array}{l}\text { Ia-f } \\ 11.0 \\ 12.3 \\ 13.1 \\ 24.0 \\ 25.7 \\ 26.0 \\ 29.5 \\ 33.4 \\ 34.2 \\ 39.9 \\ 41.0 \\ 42.1 \\ 45.6 \\ 54.5 \\ 58.1 \\ 60.2 \\ 73.6 \\ 86.5 \\ 88.7 \\ 93.0\end{array}\right]$ UGSW285

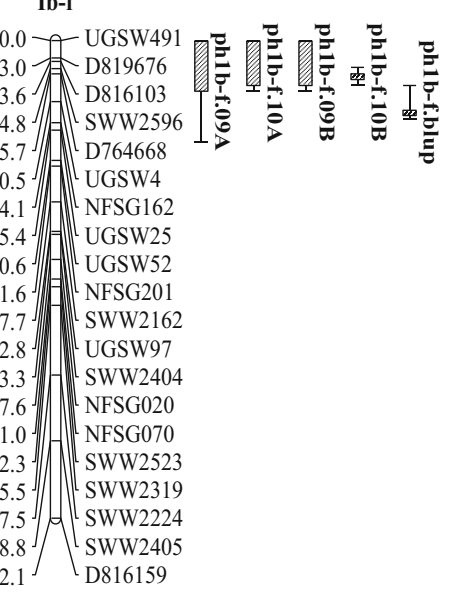

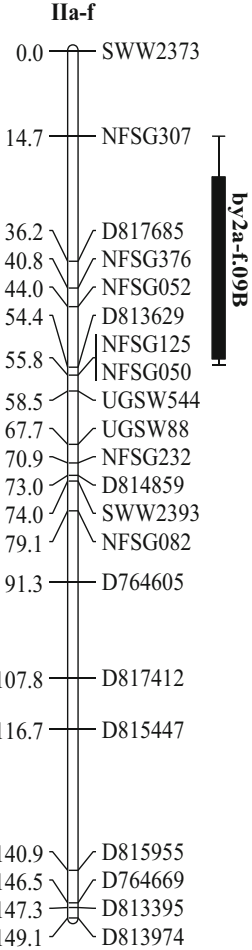

IIb-f

0.0 - $\mathrm{D} 813062$

7.7 $\begin{array}{lll}\text { DGSW314 } \\ \text { UGS174 }\end{array}$

$10.4 \widehat{D}_{\mathrm{D} 813334}$

$19.8-$ D 818790

$37.1 \sqrt{\text { NFSG085 }}$

37.1
NFSG062

49.7 D814705

$51.0-$ UGSW490

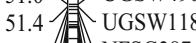

51.9 NFSG387

52.6 D819373

54.0 SWW2385

54.5 NFSG217

54.8 D814466

55.0

56.9 NFSG356

$72.1-D 815645$

79.5 SWW2165

92.4 $\mathrm{D}_{\mathrm{D} 16742}$

$104.8 \mathcal{N F S G 1 7 2}_{\text {N }}$

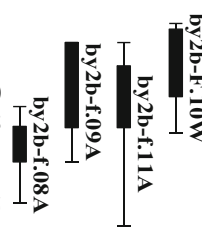

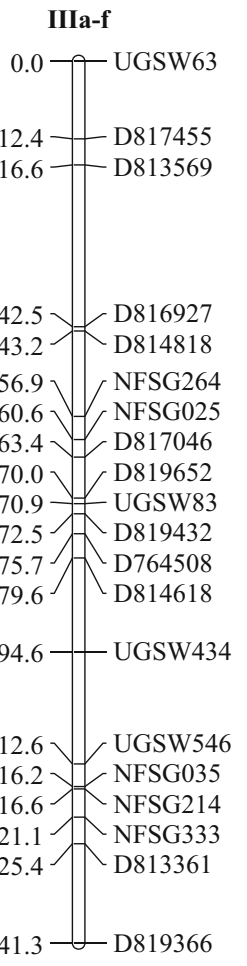

Fig. 4 QTL mapped for biomass yield and plant height in the AP13× VS16 parental linkage groups. The solid bars represent QTL for biomass yield and the bars with diagonal hatch represent QTL for plant height. The scale on the left indicates the map position of the markers and the length of each LG in centimorgan. The QTL name designation starts with the trait abbreviation (by biomass yield, $p h$ plant height), followed by linkage group number (1 to 9), arbitrary subgenome designation ("a" or
IVa-f

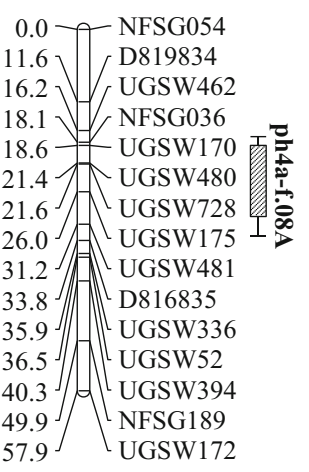

IVb-f

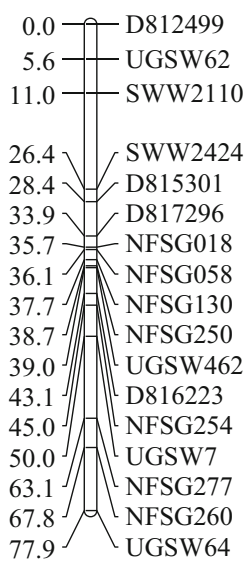

"b"), parental origin of LG ( $f$ female and $m$ male parent), last two digits of year in which phenotyping was conducted (08 to 11$)$, and ends with a location abbreviation ( $A$ Ardmore, OK; $B$ Burneyville, OK; and $W$ Watkinsville, GA). For the QTL detected with the BLUP data, the suffix BLUP was used instead of year and location. The whisker on one or both ends of the QTL chart indicates LOD scores $\geq 1.0$ but less than 2.5 

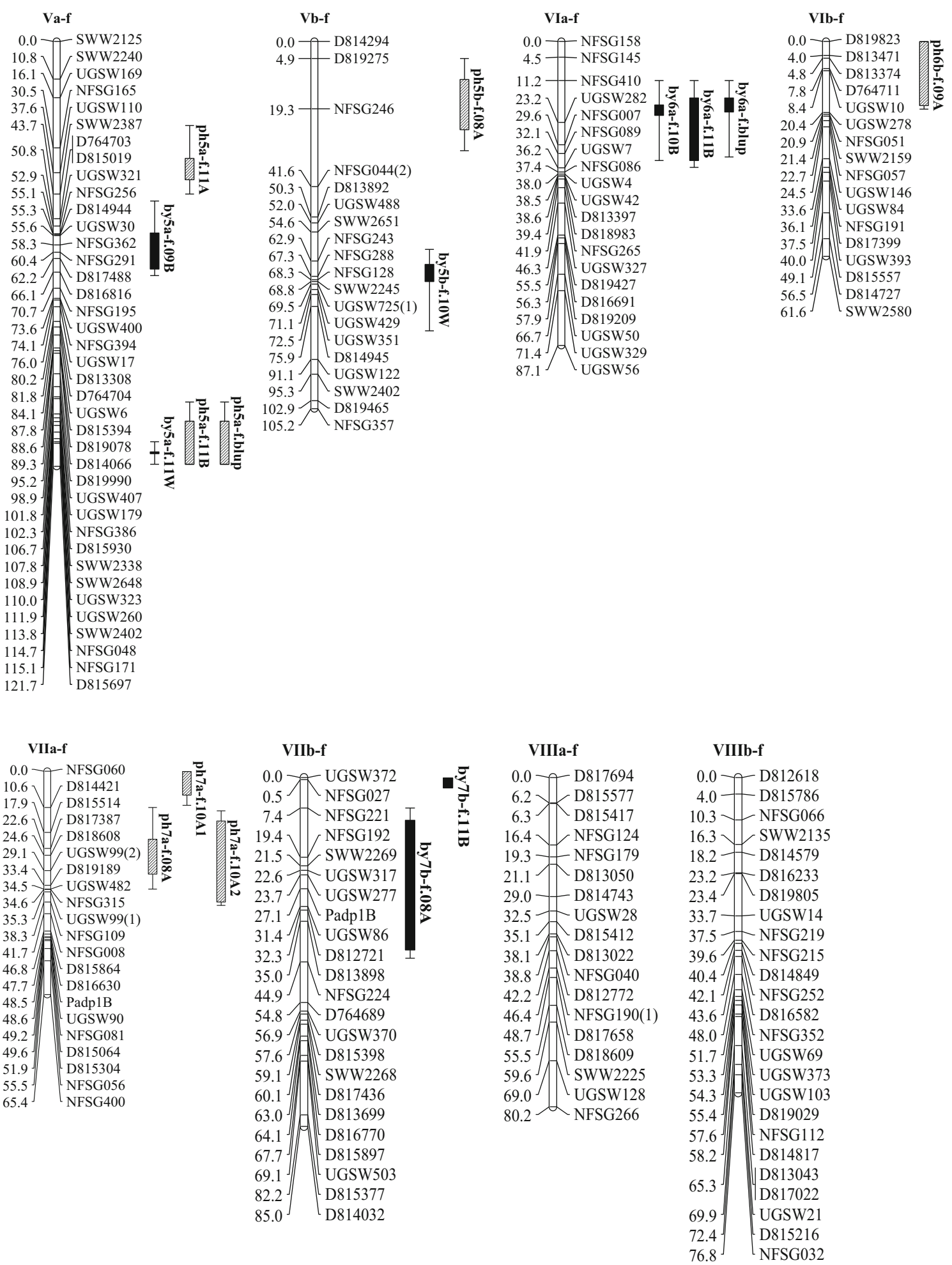

Fig. 4 (continued)

both positive and negative effects are expected in both the female (lowland) and male (upland) maps irrespective of the phenotype of the ecotype. The contribution of positive QTL effects for a trait by a parent with a nonfavorable phenotype for that trait has been demonstrated in tomato and related species [45]. In three connected populations of perennial ryegrass (L. perenne L.), per parent QTL analysis for plant height detected favorable alleles contributed by all parents 


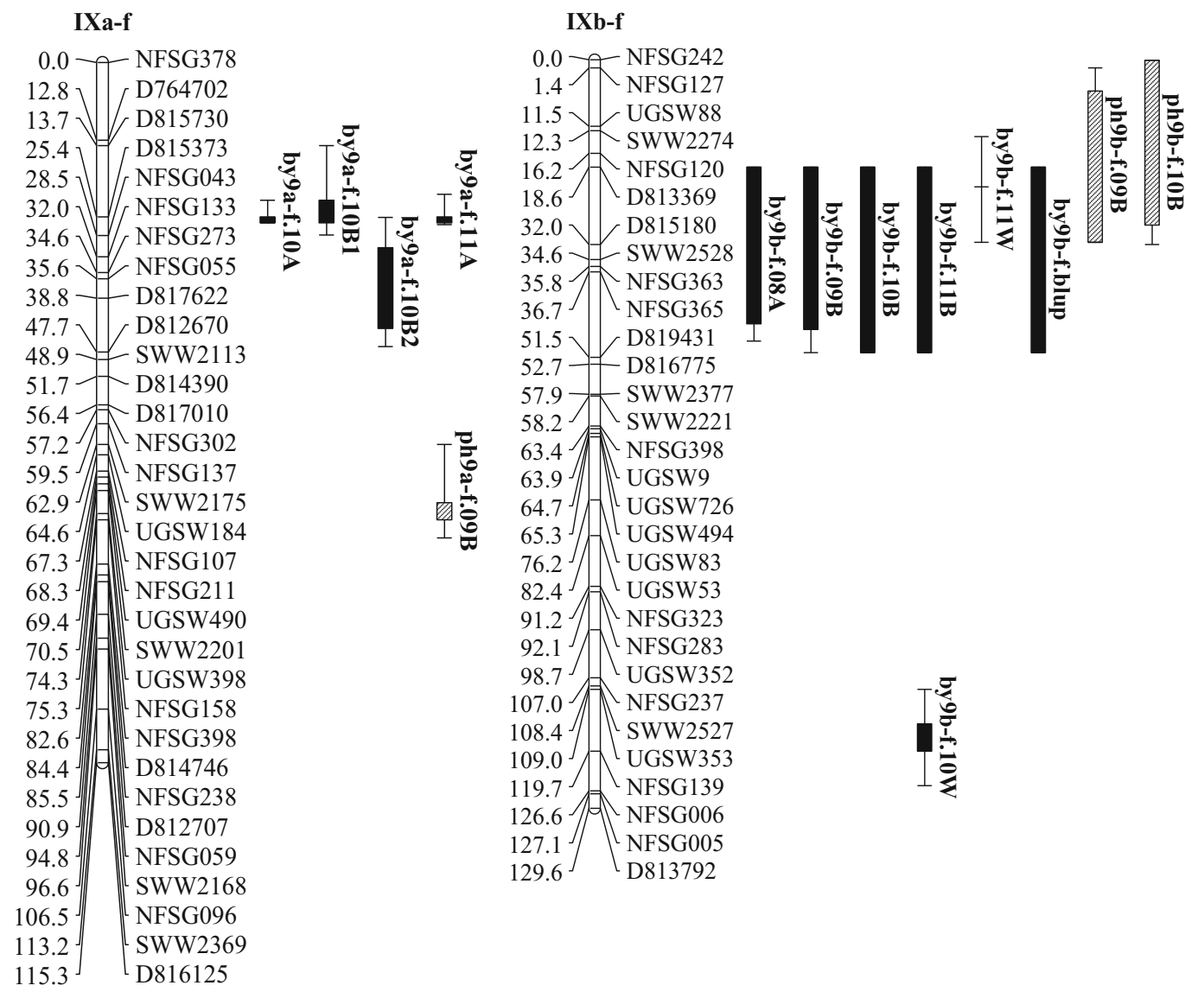

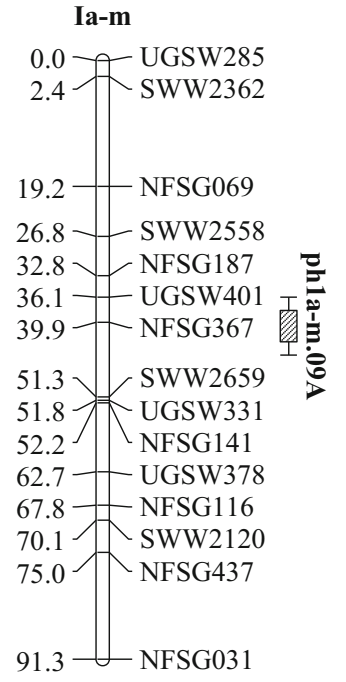

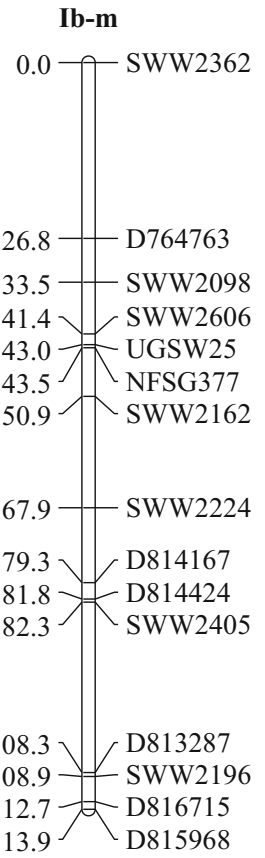

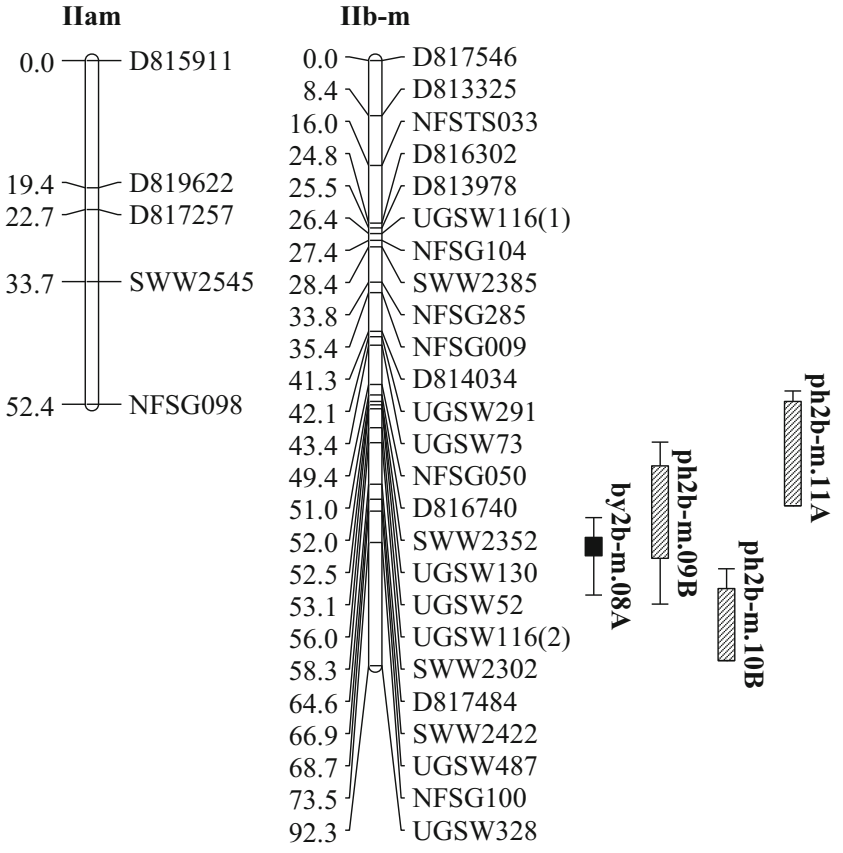

Fig. 4 (continued)

[46]. Hence, dwarf parents can contribute positive alleles for plant height as shown in wheat (Triticum aestivum L.) [47] as well as height-reducing alleles, as shown in barley (Horeium vulgare L.) [48]. Our findings also support the notion that 


\section{IIIa-m}

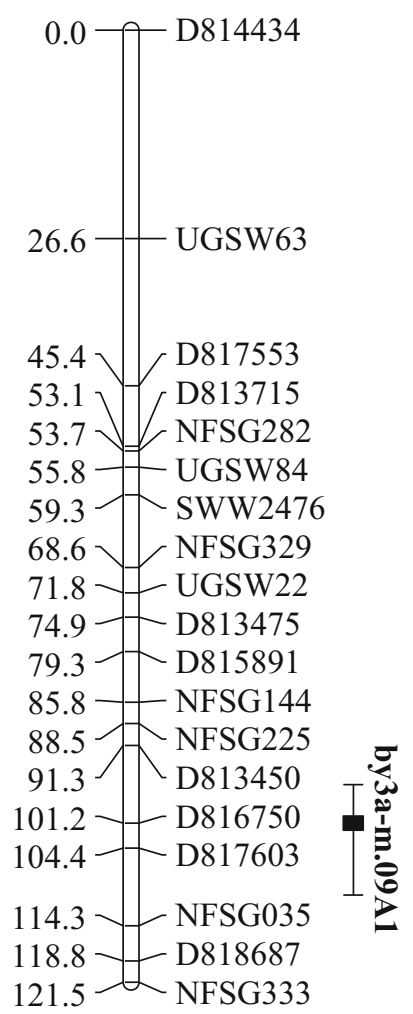

\section{IIIb-m}

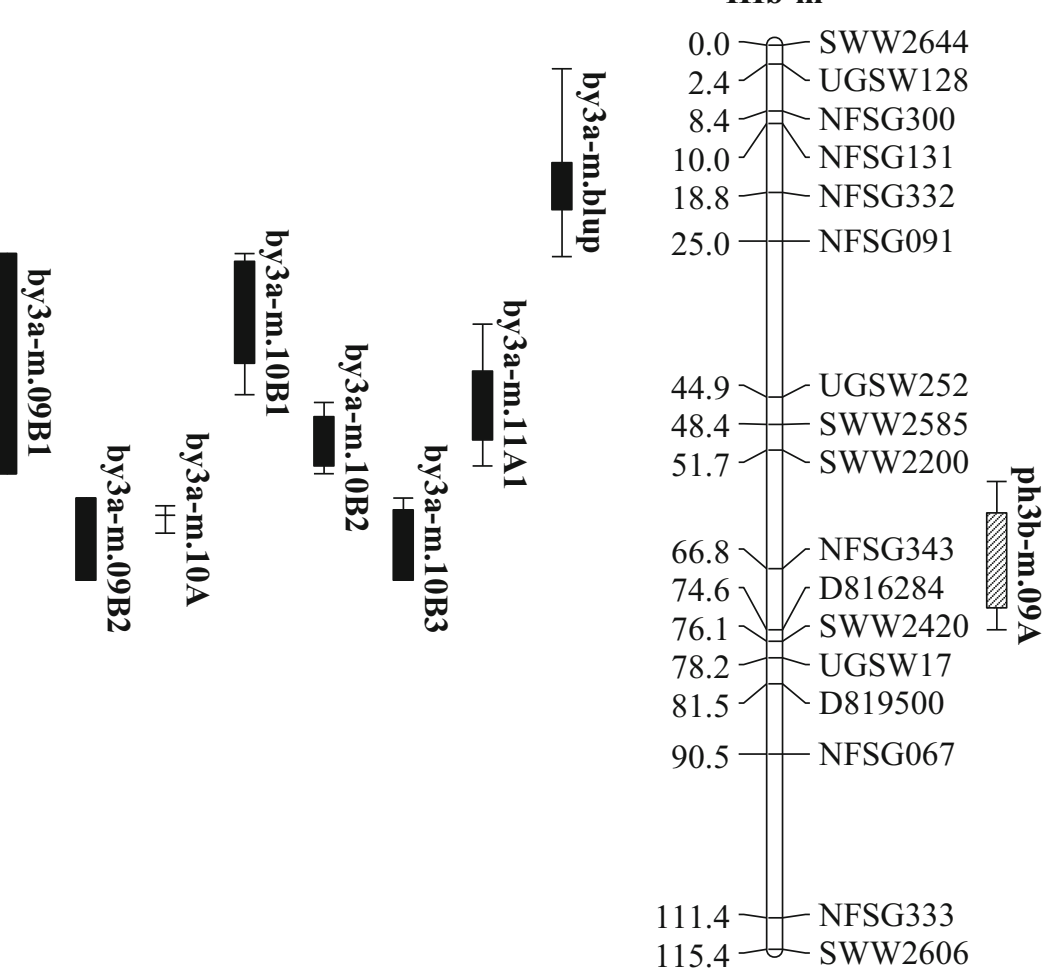

\section{IVa-m}

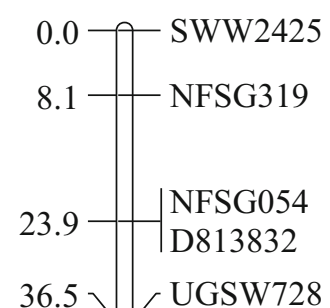

43.9 1 UGSW728

47.1 D815071

51.4 D817063

51.7 UGSW394

$51.8 \rrbracket \mathbb{D} 765082$

51.9 D815191

52.0 SWW2497

$65.6 \mathrm{D}_{\mathrm{D} 815268}$

76.2 NFSG304

$78.5 \mu_{\mathrm{D} 817300}$

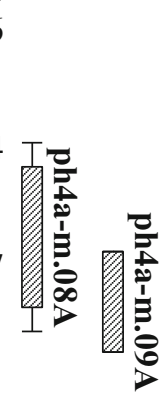

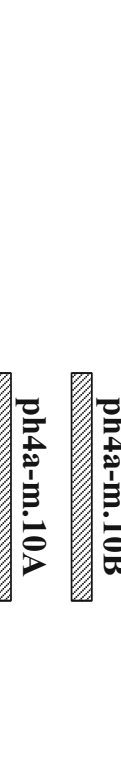

\section{IVb-m}

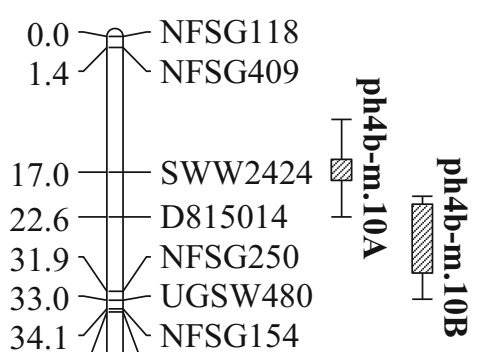

Fig. 4 (continued)

allele contribution is not limited by the phenotype of the parent [39].

Plant height QTL detected on IXb-f, IVa-m, Va-m, and IXb-m had significant $\mathrm{Q} \times \mathrm{E}$ interactions $(\mathrm{Q} \times \mathrm{E}$ LOD score $\geq 2.5$ ) (Table 4). Slight shifts in positions were observed in five
QTL consistently detected for plant height across environments (Figs. 4, 5). In addition to the main effect QTL, a total of 51 additive $\times$ additive epistatic QTL (excluding the main effect) were detected for plant height (LOD score 25.0) (Supplementary Table 2). The additive $\times$ additive 

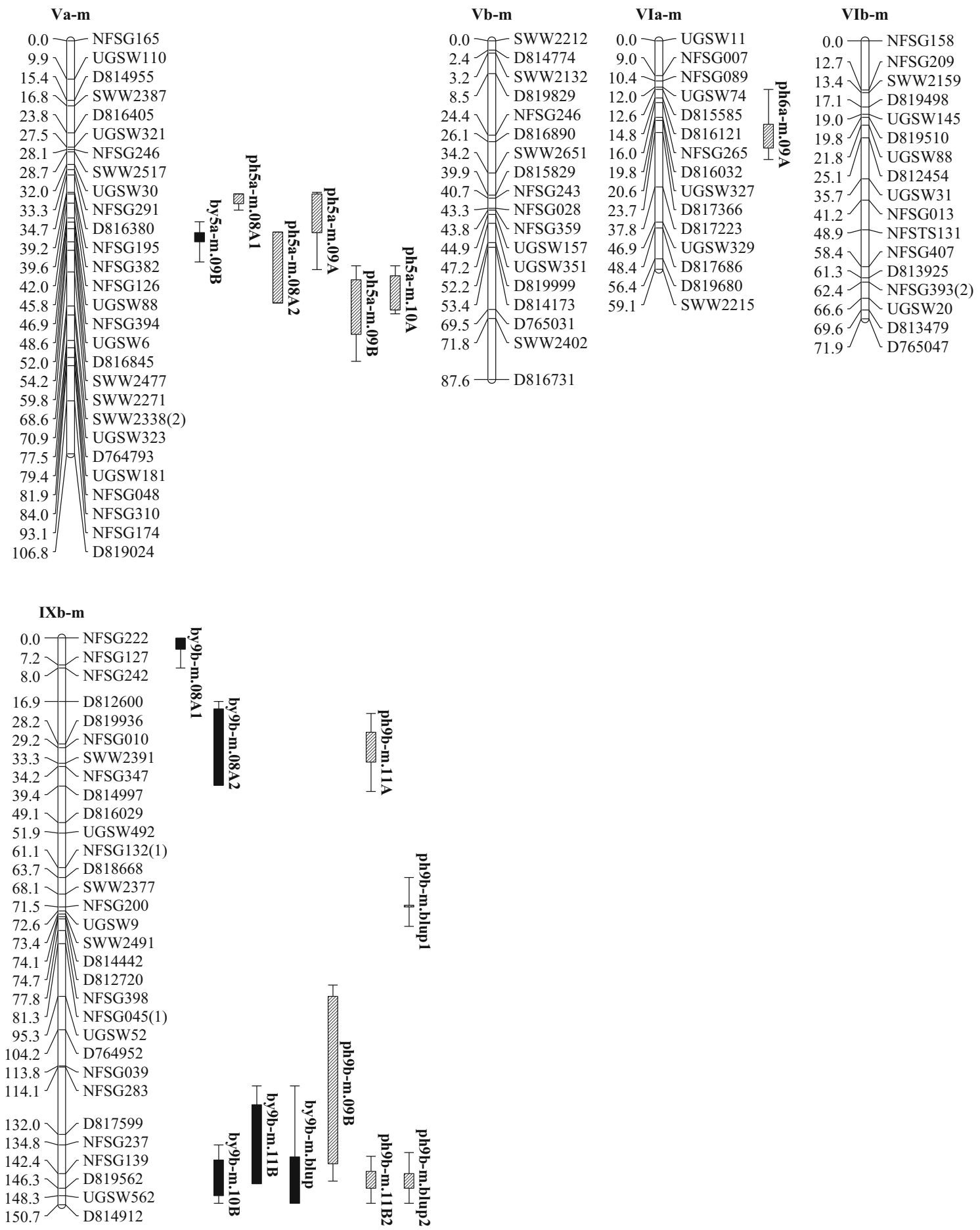

Fig. 4 (continued)

epistatic QTL effects ranged from -7 to $7 \mathrm{~cm} \mathrm{plant}^{-1}$. Digenic epistatic QTL were detected in other crops like sorghum [44], rice [49, 50], and wheat [51], signifying that both additive and epistatic QTL are important for plant height.

The distribution of plant height QTL in the switchgrass genome indicates that one or more regions of all the chromosomes are important. Similarly, QTL for plant height were detected on all ten chromosomes in sorghum [52]. Furthermore, QTL with possibly pleiotropic effects for both plant height and biomass yield were mapped on Va-m, VIIa-f, IXaf, IXa-m, and IXb-f (Fig. 4). In pseudo backcross populations derived from interspecific hybrids between basin wildrye [Leymus cinereus (Scribn. \& Merr.) A. Love] and creeping 
Table 4 Plant height QTL identified in the AP13 $\times$ VS16 switchgrass mapping population using least square means at each environment and across all environments based on best linear unbiased predictions (BLUP) estimates

\begin{tabular}{|c|c|c|c|c|c|c|c|}
\hline Мap & QTL name & LG & Position & $\mathrm{LOD}^{\mathrm{a}}$ & $\mathrm{LOD}(\mathrm{Q} \times \mathrm{E})$ & PVE & Additive effect $\left(\mathrm{cm}\right.$ plant $\left.{ }^{-1}\right)$ \\
\hline \multirow[t]{21}{*}{ Female } & ph1b-f.blup & Ib-f & 12.5 & 2.4 & - & 7.8 & 6.7 \\
\hline & ph5a-f.blup & Va-f & 111.9 & 4.4 & - & 9.0 & -7.2 \\
\hline & ph1b-f.09A & $\mathrm{Ib}-\mathrm{f}$ & 6.7 & 5.7 & 3.9 & 17.4 & 8.0 \\
\hline & ph1b-f.09B & Ib-f & 5.7 & 4.5 & 3.9 & 9.1 & 8.0 \\
\hline & ph1b-f.10A & $\mathrm{Ib}-\mathrm{f}$ & 5.7 & 4.1 & 3.9 & 9.5 & 6.4 \\
\hline & ph7a-f.10A1 & VIIa-f & 1.0 & 4.3 & 2.5 & 8.7 & 6.1 \\
\hline & ph1b-f.10B & Ib-f & 5.7 & 2.5 & 3.9 & 6.6 & 5.9 \\
\hline & ph7a-f.10A2 & VIIa-f & 35.3 & 3.6 & - & 7.1 & 5.6 \\
\hline & ph6b-f.09A & VIb-f & 4.0 & 3.6 & - & 7.1 & 5.2 \\
\hline & ph4a-f.08A & IVa-f & 21.6 & 3.1 & 4.2 & 6.4 & 5.1 \\
\hline & ph7a-f.08A & VIIa-f & 25.6 & 2.9 & - & 6.1 & 5.0 \\
\hline & ph5a-f.11A & Va-f & 36.5 & 2.8 & - & 6.3 & 4.2 \\
\hline & ph5b-f.08A & Vb-f & 17.9 & 2.6 & - & 5.3 & -4.8 \\
\hline & ph9b-f.09B & IXb-f & 16.2 & 3.3 & - & 6.1 & -5.9 \\
\hline & ph9a-f.09B & IXa-f & 74.3 & 2.8 & 2.7 & 6.0 & -5.9 \\
\hline & ph9b-f.10B & IXb-f & 16.2 & 3.6 & - & 7.5 & -6.3 \\
\hline & ph5a-f.11B & Va-f & 111.9 & 4.4 & - & 9.0 & -7.1 \\
\hline & \multicolumn{7}{|c|}{ Additional QTL with LOD score 2.3 to 2.4} \\
\hline & ph7a-f.09A & VIIa-f & 49.6 & 2.4 & - & 4.4 & 4.0 \\
\hline & ph1b-f.11B & Ib-f & 12.5 & 2.4 & 3.9 & 7.6 & 6.6 \\
\hline & ph4b-f.09W & IVb-f & 35.7 & 2.3 & 3.3 & 4.9 & 4.2 \\
\hline \multirow[t]{26}{*}{ Male } & ph4a-m.blup & IVa-m & 59.0 & 5.4 & - & 12.0 & -8.3 \\
\hline & ph9b-m.blup 1 & IXb-m & 71.5 & 2.6 & - & 5.1 & 5.4 \\
\hline & ph9b-m.blup2 & IXb-m & 144.4 & 2.6 & - & 5.3 & -5.5 \\
\hline & ph2b-m.10B & IIb-m & 91.5 & 4.3 & 2.5 & 8.5 & 6.8 \\
\hline & ph4b-m.10B & IVb-m & 24.6 & 2.8 & - & 5.7 & 5.5 \\
\hline & ph6a-m.09A & VIa-m & 23.6 & 3.2 & - & 6.5 & 4.8 \\
\hline & ph3b-m.09A & IIIb-m & 66.7 & 3.1 & 2.7 & 5.7 & 4.6 \\
\hline & ph4b-m.10A & IVb-m & 16.4 & 2.5 & - & 4.6 & 4.5 \\
\hline & ph9b-m.11A & IXb-m & 132.0 & 3.0 & - & 5.9 & -4.0 \\
\hline & ph2b-m.11A & IIb-m & 58.3 & 3.8 & 5.8 & 7.2 & -4.4 \\
\hline & phla-m.11A & Ia-m & 39.9 & 3.1 & - & 5.8 & -4.8 \\
\hline & ph5a-m.10B & Va-m & 66.8 & 2.5 & - & 4.4 & -4.8 \\
\hline & ph4a-m.11A & IVa-m & 70.6 & 4.2 & 4.3 & 9.4 & -5.0 \\
\hline & ph4a-m.08A & IVa-m & 64.0 & 3.3 & 4.3 & 6.9 & -5.3 \\
\hline & ph5a-m.08A1 & Va-m & 40.6 & 3.2 & 2.7 & 6.7 & -5.3 \\
\hline & ph5a-m.10A & Va-m & 65.8 & 3.5 & - & 7.2 & -5.5 \\
\hline & ph9b-m.11B2 & IXb-m & 144.4 & 2.6 & - & 5.4 & -5.5 \\
\hline & ph4a-m.10A & IVa-m & 51.7 & 3.9 & 2.5 & 7.4 & -5.7 \\
\hline & ph5a-m.08A2 & Va-m & 52.0 & 4.3 & 2.7 & 8.4 & -5.9 \\
\hline & ph5a-m.09A & Va-m & 43.0 & 3.4 & 2.7 & 9.4 & -5.9 \\
\hline & ph2b-m.09B & Ilb-m & 53.1 & 2.8 & 5.8 & 5.9 & -5.9 \\
\hline & ph5a-m.09B & Va-m & 65.8 & 3.2 & - & 7.6 & -6.6 \\
\hline & ph4a-m.10B & IVa-m & 51.7 & 4.4 & 2.5 & 8.2 & -6.7 \\
\hline & ph4a-m.09A & IVa-m & 78.2 & 6.9 & 4.3 & 13.7 & -7.1 \\
\hline & ph9b-m.09B & IXb-m & 122.1 & 3.9 & - & 9.7 & -7.5 \\
\hline & ph4a-m.11B & IVa-m & 58.0 & 5.0 & 2.5 & 12.0 & -8.2 \\
\hline
\end{tabular}


Table 4 (continued)

\begin{tabular}{|c|c|c|c|c|c|c|c|}
\hline Map & QTL name & LG & Position & $\mathrm{LOD}^{\mathrm{a}}$ & $\mathrm{LOD}(\mathrm{Q} \times \mathrm{E})$ & PVE & Additive effect $\left(\mathrm{cm} \mathrm{plant}^{-1}\right)$ \\
\hline & \multicolumn{7}{|c|}{ Additional QTL with LOD score 2.0 to 2.4} \\
\hline & ph1b-m.09W & Ib-m & 42.4 & 2.4 & - & 8.3 & 5.4 \\
\hline & ph6a-m.09W & VIa-m & 20.6 & 2.3 & - & 4.9 & 4.1 \\
\hline & ph9b-m.11B1 & $\mathrm{IXb}-\mathrm{m}$ & 71.5 & 2.2 & 3.8 & 4.3 & 5.0 \\
\hline & ph4a-m.09W & IVa-m & 22.1 & 2.0 & - & 4.3 & -3.9 \\
\hline
\end{tabular}

The QTL name designation starts with the trait abbreviation ( $p$ plant height), followed by the linkage group number (1 to 9), subgenome designation ("a" or "b"), parental origin of linkage group ( $f$ female and $m$ male), last two digits of year in which phenotyping was conducted ( 08 to 11$)$ and ends with location abbreviation ( $A$ Ardmore, OK; $B$ Burneyville, OK; and $W$ Watkinsville, GA). QTL detected with BLUP data were suffixed with "BLUP" instead of year and location

$L O D(A)$ logarithm of odds for the additive effect, $L O D(Q \times E)$ logarithm of odds for the QTL $\times$ environment effect, "--" data not available, $P V E$ phenotypic variation explained

${ }^{a}$ QTL with LOD score range 2.0 to 2.4 were included

wildrye [Leymus triticoides (Buckley)], most of the plant height QTL overlapped with biomass QTL [53]. Using markers to select for these QTL would simultaneously increase biomass yield and plant height.

\section{QTL Effects and Implications for Switchgrass Breeding}

Switchgrass is an outcrossing species and most of the commercial cultivars are synthetics comprising a heterogeneous mixture of heterozygous genotypes. A high level of within population genetic variation is a common feature in switchgrass which provides buffering against biotic and abiotic stresses [54]. Progress to enhance switchgrass for yield and other traits using phenotypic selection has been demonstrated empirically $[5,8$, $9,55]$. The main purpose of QTL mapping is to identify markers that can be applied in marker-assisted breeding to improve genetic gains for traits of interest. The QTL for biomass yield and plant height that we identified have additive effects that are promising to expedite breeding programs and to maximize gain per selection cycle. Some QTL have possibly pleiotropic effects allowing selection for plant height as a contributing trait for biomass yield. The QTL identified could be useful to initiate rapid screening of populations in order to select superior parents for hybrid breeding, to accumulate desirable alleles in a population through marker-only selection, or to enable two or more cycles of selection to be completed within a year. This QTL
Fig. 5 LOD curves and additive effect of QTL mapped for plant height on linkage group IVa-m across seven environments and using BLUP for across all environments

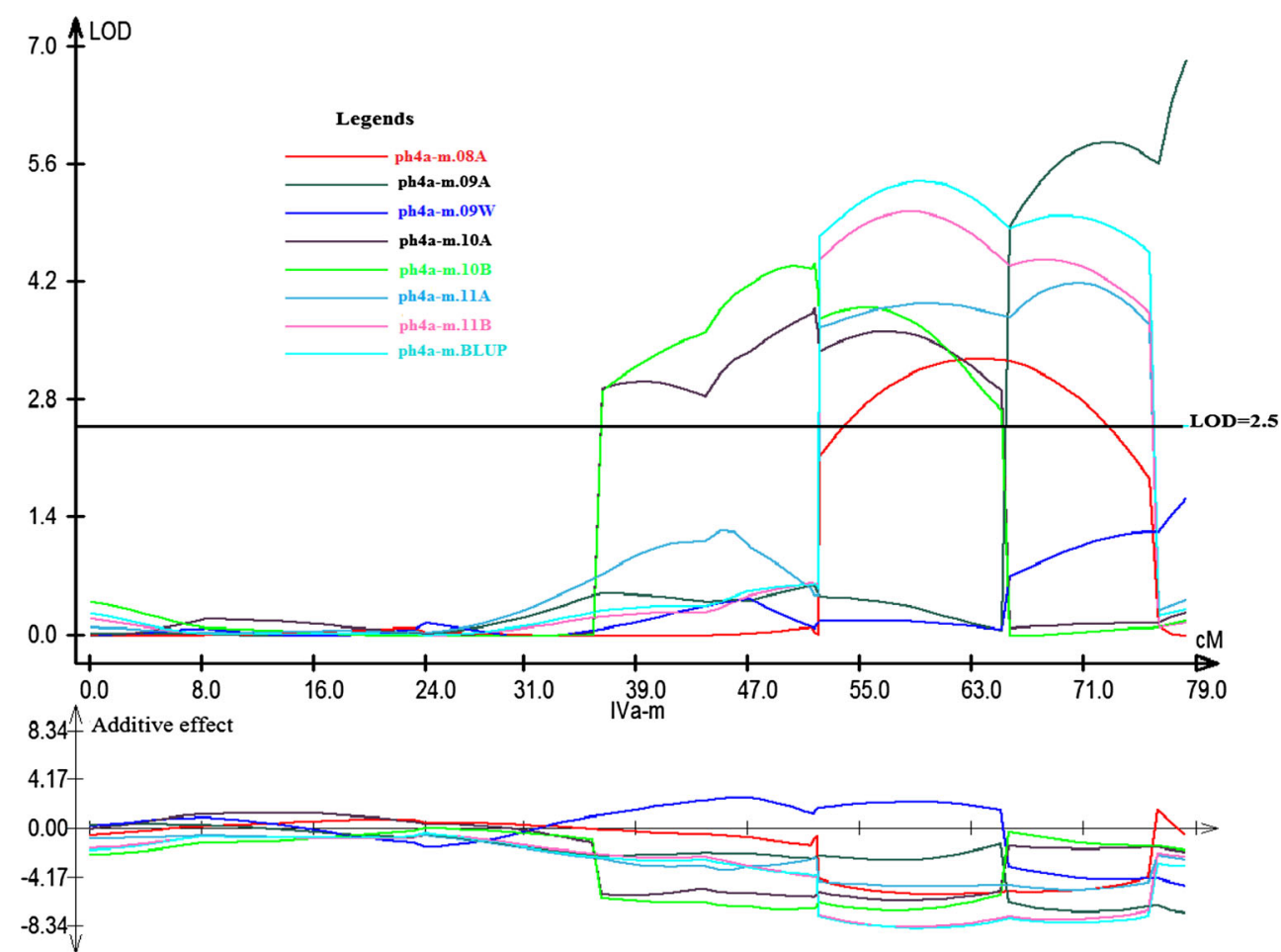


study will also assist with QTL validation in other populations and fine mapping and cloning of QTL to ultimately enhance our understanding of agronomically important traits and their optimal selection in breeding programs.

Nevertheless, the QTL detected in female and male homoeologous LGs were in different arms. For instance, the plant height QTL consistently detected on IVa-m was not detected in IVa-f, except ph4a-f.08A which is mapped in the opposite arm and flanked by different set of markers than observed in IVa-m. The same is true with the biomass QTL detected in IXb-f. None of these QTL were detected in the corresponding position of LG Ixb-m. This noncorrespondence of the QTL between the female and male maps indicates that biomass and plant height QTL may be different in the female (lowland) and the male (upland) maps (ecotypes).

\section{Conclusion}

A biparental pseudo- $\mathrm{F}_{1}$ mapping population was developed by crossing two distinct genotypes, AP13 (lowland) and VS16 (upland). The mapping population varied for both biomass yield and plant height enabling us to identify main effect and epistatic QTL controlling the traits. Both parents contributed favorable alleles to both traits, and at least some QTL effects varied across environments. To the best of our knowledge, this is the first QTL mapping report in switchgrass. We identified 11 important genomic regions controlling both traits. Markers associated with the traits in these 11 regions provide an important tool toward the development of a MAS program in switchgrass breeding.

Acknowledgments This research work was funded by the BioEnergy Science Center, a U.S. Department of Energy Bioenergy Research Center supported by the Office of Biological and Environmental Research in the DOE Office of Science. The authors thank Brian Motes and his group at the Noble Foundation for field plot management at Ardmore and Burneyville, Oklahoma. We thank Donald Wood, Jonathan Markham, and Wesley Dean at the University of Georgia for their assistance managing the field experiment at Watkinsville, Georgia.

Open Access This article is distributed under the terms of the Creative Commons Attribution License which permits any use, distribution, and reproduction in any medium, provided the original author(s) and the source are credited.

\section{References}

1. Brereton N, Pitre F, Hanley S, Ray M, Karp A, Murphy R (2010) QTL mapping of enzymatic saccharification in short rotation coppice willow and its independence from biomass yield. BioEnergy Res 3(3):251-261
2. Rooney WL, Blumenthal J, Bean B, Mullet JE (2007) Designing sorghum as a dedicated bioenergy feedstock. Biofuels Bioprod Biorefin 1(2):147-157

3. EIA (2007) International Energy Outlook 2007. Washington, DC, USA. Available at: www.eia.doe.gov/oiaf/ieo/index.html

4. Simmons B, Loque D, Blanch H (2008) Next-generation biomass feedstocks for biofuel production. Genome Biol 9(12):242

5. Bouton J (2008) Improvement of switchgrass as a bioenergy crop. In: Vermerris W (ed) Genetic improvement of bioenergy crops. Springer Science + Business Media, New York

6. Vogel KP, Mitchell KB (2008) Heterosis in switchgrass: biomass yield in swards. Crop Sci 48(6):2159-2164

7. Yang J, Zhu J, Williams RW (2007) Mapping the genetic architecture of complex traits in experimental populations. Bioinforma (Oxford) 23(12):1527-1536

8. Bhandari HS, Saha MC, Fasoula VA, Bouton JH (2011) Estimation of genetic parameters for biomass yield in lowland switchgrass (Panicum virgatum L.). Crop Sci 51(4):1525-1533

9. Bhandari HS, Saha MC, Mascia PN, Fasoula VA, Bouton JH (2010) Variation among half-sib families and heritability for biomass yield and other traits in lowland switchgrass (Panicum virgatum L.). Crop Sci 50(6):2355-2363

10. Casler MD (2010) Changes in mean and genetic variance during two cycles of within-family selection in switchgrass. BioEnergy Res 3(1, Sp. Iss. SI):47-54

11. Missaoui AM, Fasoula VA, Bouton JH (2005) The effect of low plant density on response to selection for biomass production in switchgrass. Euphytica 142(1-2):1-12

12. Casler MD (2012) Switchgrass breeding, genetics, and genomics. In: Monti A (ed) Switchgrass, green energy and technology. Springer, London, pp 29-53

13. Serba D, Wu L, Daverdin G, Bahri BA, Wang X, Kilian A, Bouton JH, Brummer EC, Saha MC, Devos KM (2013) Linkage maps of lowland and upland tetraploid switchgrass ecotypes. BioEnergy Res 6(3):953-965

14. Fasoulas AC, Fasoula VA (2010) Honeycomb selection designs. Plant Breeding Reviews. Wiley, pp 87-139

15. Henderson CR (1975) Best linear unbiased estimation and prediction under a selection model. Biometrics 31(2):423-447

16. Littell RC, Milliken GA, Stroup WW, Wolfinger RD (1996) SAS system for mixed models. SAS Institute Inc., Cary

17. Wang J, Li H, Zhang L, Meng L (2012) QTL IciMapping Version 3.2

18. Weller JI (1986) Maximum likelihood techniques for the mapping and analysis of quantitative trait loci with the aid of genetic markers. Biometrics 42(3):627-640

19. Lander ES, Botstein D (1989) Mapping Mendelian factors underlying quantitative traits using RFLP linkage maps. Genet 121(1):185-199

20. Silva L, Wang S, Zeng Z-B (2012) Composite interval mapping and multiple interval mapping: procedures and guidelines for using Windows QTL Cartographer. In: Rifkin SA (ed) Quantitative trait loci (QTL), vol 871. Methods in molecular biology. Humana, New York, pp 75-119

21. Li H, Ribaut JM, Li Z, Wang J (2008) Inclusive composite interval mapping (ICIM) for digenic epistasis of quantitative traits in biparental populations. Theor Appl Genet 116(2):243-260

22. Li H, Ye G, Wang J (2007) A modified algorithm for the improvement of composite interval mapping. Genet 175(1):361-374

23. Fuentes RG, Taliaferro CM (2002) Biomass yield stability of switchgrass cultivars. In: Janick J, Whipkey A (eds) Trends in new crops and new uses. Proceedings of the Fifth National Symposium, Atlanta, Georgia, USA, 10-13 November, 2001. ASHS Press, Alexandria, pp 276-282

24. Casler MD, Boe AR (2003) Cultivar $\times$ environment interactions in switchgrass. Crop Sci 43(6):2226-2233

25. Das MK, Fuentes RG, Taliaferro CM (2004) Genetic variability and trait relationships in switchgrass. Crop Sci 44(2):443-448 
26. Alexopoulou E, Sharma N, Papatheohari Y, Christou M, Piscioneri I, Panoutsou C, Pignatelli V (2008) Biomass yields for upland and lowland switchgrass varieties grown in the Mediterranean region. Biomass Bioenergy 32(10):926-933

27. Salas Fernandez MG, Becraft PW, Yin Y, Lübberstedt T (2009) From dwarves to giants? Plant height manipulation for biomass yield. Trends Plant Sci 14(8):454-461

28. Freeman KW, Girma K, Arnall DB, Mullen RW, Martin KL, Teal RK, Raun WR (2007) By-plant prediction of corn forage biomass and nitrogen uptake at various growth stages using remote sensing and plant height. Agron J 99(2):530-536

29. Rae AM, Pinel MPC, Bastien C, Sabatti M, Street NR, Tucker J, Dixon C, Marron N, Dillen SY, Taylor G (2007) QTL for yield in bioenergy populus: identifying $\mathrm{G} \times \mathrm{E}$ interactions from growth at three contrasting sites. Tree Genet Genomes 4(1):97-112

30. Muchero W, Sewell MM, Ranjan P, Gunter LE, Tschaplinski TJ, Yin T, Tuskan GA (2013) Genome anchored QTLs for biomass productivity in hybrid populus grown under contrasting environments. PLoS One 8(1):e54468. doi:10.1371/journal.pone.0054468

31. Rae AM, Street NR, Robinson KM, Harris N, Taylor G (2009) Five QTL hotspots for yield in short rotation coppice bioenergy poplar: the poplar biomass loci. BMC Plant Biol 9:23

32. Lu Y, Xu J, Yuan Z, Hao Z, Xie C, Li X, Shah T, Lan H, Zhang S, Rong T, Xu Y (2012) Comparative LD mapping using single SNPs and haplotypes identifies QTL for plant height and biomass as secondary traits of drought tolerance in maize. Mol Breed 30(1): $407-418$

33. Robins JG, Bauchan GR, Brummer EC (2007) Genetic mapping forage yield, plant height, and regrowth at multiple harvests in tetraploid alfalfa (Medicago sativa L.). Crop Sci 47(1):11-18

34. Robins JG, Luth D, Campbell TA, Bauchan GR, He C, Viands DR, Hansen JL, Brummer EC (2007) Genetic mapping of biomass production in tetraploid alfalfa. Crop Sci 47(1):1

35. Liu G-F, Yang J, Zhu J (2006) Mapping QTL for biomass yield and its components in rice (Oryza sativa L.). Acta Genet Sin 33(7):607-616

36. Anhalt UCM, Heslop-Harrison JS, Piepho HP, Byrne S, Barth S (2009) Quantitative trait loci mapping for biomass yield traits in a Lolium inbred line derived F-2 population. Euphytica 170(1-2):99-107

37. Hoarau JY, Grivet L, Offmann B, Raboin LM, Diorflar JP, Payet J, Hellmann M, D'Hont A, Glaszmann JC (2002) Genetic dissection of a modern sugarcane cultivar (Saccharum spp.). II. Detection of QTLs for yield components. Theor Appl Genet 105(6-7):1027-1037

38. Pastina MM, Malosetti M, Gazaffi R, Mollinari M, Margarido GRA, Oliveira KM, Pinto LR, Souza AP, van Eeuwijk FA, Garcia AAF (2012) A mixed model QTL analysis for sugarcane multiple-harvestlocation trial data. Theor Appl Genet 124(5):835-849

39. Singh RK, Singh SP, Tiwari DK, Srivastava S, Singh SB, Sharma ML, Singh R, Mohapatra T, Singh NK (2013) Genetic mapping and QTL analysis for sugar yield-related traits in sugarcane. Euphytica 191(3):333-353

40. Guan Y-a, Wang H-l, Qin L, Zhang H-w, Yang Y-b, Gao F-j, Li R-y, Wang H-g (2011) QTL mapping of bio-energy related traits in sorghum. Euphytica 182(3):431-440
41. Zhang L, Wang S, Li H, Deng Q, Zheng A, Li S, Li P, Li Z, Wang J (2010) Effects of missing marker and segregation distortion on QTL mapping in F2 populations. Theor Appl Genet 121(6):1071-1082

42. Atienza SG, Satovic Z, Petersen KK, Dolstra O, Martin A (2003) Identification of QTLs influencing agronomic traits in Miscanthus sinensis Anderss. I. Total height, flag-leaf height and stem diameter. Theor Appl Genet 107(1):123-129

43. Quinby JR (1974) Sorghum improvement and the genetics of growth. Texas Agricultural Experiment Station, College Station

44. Brown PJ, Rooney WL, Franks C, Kresovich S (2008) Efficient mapping of plant height quantitative trait loci in a sorghum association population with introgressed dwarfing genes. Genet 180(1):629 637

45. Tanksley SD, Grandillo S, Fulton TM, Zamir D, Eshed Y, Petiard V, Lopez J, Beck-Bunn T (1996) Advanced backcross QTL analysis in a cross between an elite processing line of tomato and its wild relative L. pimpinellifolium. Theor Appl Genet 92(2):213-224

46. Pauly L, Flajoulot S, Garon J, Julier B, Beguier V, Barre P (2012) Detection of favorable alleles for plant height and crown rust tolerance in three connected populations of perennial ryegrass (Lolium perenne L). TAG Theor Appl Genet 124(6):1139-1153

47. Sadeque A, Turner MA (2010) QTL analysis of plant height in hexaploid wheat doubled haploid population. Thai J Agric Sci 43(2):91-96

48. Shahinnia F, Rezai A, Sayed-Tabatabaei BE, Komatsuda T, Mohammadi SA (2006) QTL mapping of heading date and plant height in barley cross "Azumamugi" * "Kanto Nakate Gold". Iran J Biotechnol 4(2):88-94

49. Cao G-Q, Zhu J, He C-X, Gao Y-M, Wu P (2001) QTL analysis for epistatic effects and QTL X environment interaction effects on final height of rice (Oryza sativa L.). Acta Genet Sin 28(2):135-143

50. Yu SB, Li JX, Xu CG, Tan YF, Li XH, Zhang Q (2002) Identification of quantitative trait loci and epistatic interactions for plant height and heading date in rice. Theor Appl Genet 104(4):619-625

51. Zhang K, Tian J, Zhao L, Wang S (2008) Mapping QTLs with epistatic effects and QTL $\times$ environment interactions for plant height using a doubled haploid population in cultivated wheat. J Genet Genomics 35(2):119-127

52. Feltus FA, Hart GE, Schertz KF, Casa AM, Kresovich S, Abraham S, Klein PE, Brown PJ, Paterson AH (2006) Alignment of genetic maps and QTLs between inter- and intraspecific sorghum populations. Theor Appl Genet 112:1295-1305

53. Larson SR, Jensen KB, Robins JG, Waldron BL (2014) Genes and quantitative trait loci controlling biomass yield and forage quality traits in perennial wildrye. Crop Sci 54(1):111-126

54. Uppalapati SR, Serba DD, Ishiga Y, Szabo LJ, Mittal S, Bhandari HS, Bouton JH, Mysore KS, Saha MC (2013) Characterization of the rust fungus, Puccinia emaculata, and evaluation of genetic variability for rust resistance in switchgrass populations. BioEnergy Res 6(2):458468

55. Casler MD, Smart AJ (2013) Plant mortality and natural selection may increase biomass yield in switchgrass swards. Crop Sci 53(2): 500-506 